\title{
How clinical imaging can assess cancer biology
}

\author{
Roberto García-Figueiras **, Sandra Baleato-González ${ }^{1}$, Anwar R. Padhani², Antonio Luna-Alcaláa, \\ Juan Antonio Vallejo-Casas ${ }^{5}$, Evis Sala ${ }^{6}$, Joan C. Vilanova ${ }^{7}$, Dow-Mu Koh ${ }^{8}$, Michel Herranz-Carnero ${ }^{9,10}$ and \\ Herbert Alberto Vargas ${ }^{11}$
}

\begin{abstract}
Human cancers represent complex structures, which display substantial inter- and intratumor heterogeneity in their genetic expression and phenotypic features. However, cancers usually exhibit characteristic structural, physiologic, and molecular features and display specific biological capabilities named hallmarks. Many of these tumor traits are imageable through different imaging techniques. Imaging is able to spatially map key cancer features and tumor heterogeneity improving tumor diagnosis, characterization, and management. This paper aims to summarize the current and emerging applications of imaging in tumor biology assessment.
\end{abstract}

Keywords: Neoplasms, Phenotype, Multimodal imaging

\section{Key points}

- Tumors demonstrate substantial inter- and intratumor heterogeneity in their biological features

- Imaging techniques may improve the assessment of tumor-specific characteristics in clinical practice.

- Functional and molecular imaging techniques may depict tumor heterogeneity.

\section{Introduction}

Imaging techniques have emerged as exceptionally powerful, versatile, and precise tools for assessing relevant tumor characteristics. Cancers usually display several structural, physiologic, and molecular changes and common acquired biological capabilities that can be evaluated with imaging $[1,2]$. Besides, tumors demonstrate substantial inter- and intratumor heterogeneity in their biological features [3]. A modern personalized oncologic approach requires a deeper understanding of these cancer traits for being implemented in patient care. Functional-molecular imaging (FMI) information in addition to morphologic/anatomical changes can simultaneously assess a multitude of biological cancerrelated processes, improving our diagnostic accuracy and

\footnotetext{
* Correspondence: roberto.garcia.figueiras@sergas.es

${ }^{1}$ Department of Radiology, Hospital Clínico Universitario de Santiago de

Compostela, Choupana s/n, 15706 Santiago de Compostela, Spain

Full list of author information is available at the end of the article
}

the assessment of response to therapy [4]. Different imaging techniques are useful for this role, including dynamic contrast-enhanced MRI (DCE-MRI), DCEultrasound (US), dynamic susceptibility contrastenhanced MRI (DSC-MRI), perfusion CT (PCT), diffusion-weighted imaging (DWI), and magnetic resonance spectroscopy (MRS) and spectroscopic imaging (MRSI), arterial spin-labeling (ASL), blood oxygenation level-dependent MR imaging (BOLD-MRI), elastography, positron emission tomography (PET), or single-photon emission computed tomography (SPECT) imaging (Fig. 1) (Additional file 1: Table S1). These imaging techniques enable the evaluation of unseen tumor characteristics by conventional techniques improving tumor diagnosis and management $[4,5]$. In this ssetting, the biological and physiological correlations of imaging parameters (which depend on tumor type, imaging technique, and technical questions) need to be established and the limitations and possible pitfalls of every imaging technique must be asessed. This paper aims to summarize the role of imaging in the assessment of tumor biology.

\section{Imaging for the evaluation of tumor biology}

Imaging techniques are increasingly being used to perform a noninvasive assessment of tumor biology in clinical practice. Imaging offers an adequate combination of 


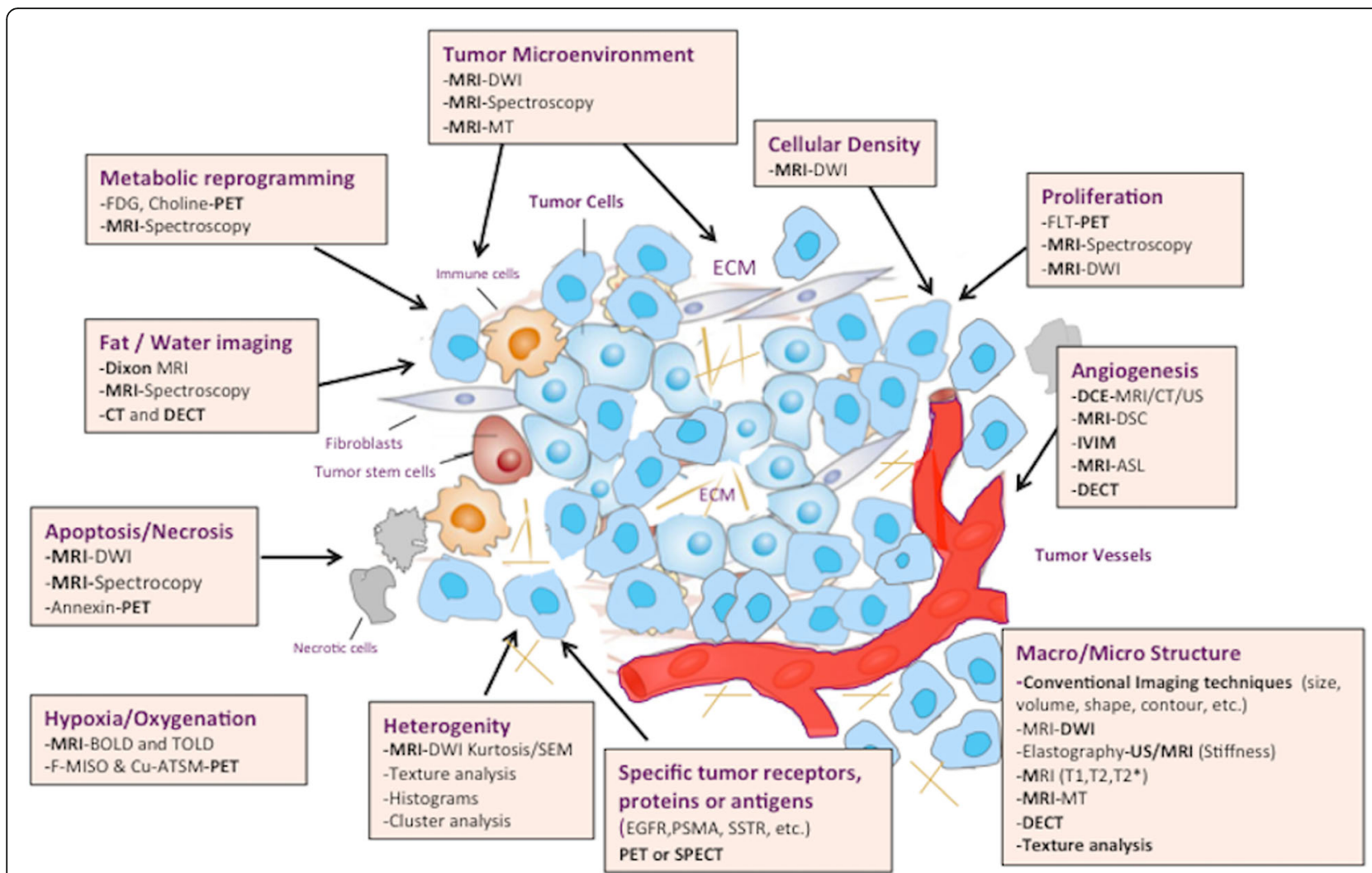

Fig. 1 Main imaging techniques in the evaluation of tumor biology and microenvinroment

anatomic, physiologic, and molecular information for evaluating cancer phenotype in vivo at different levels [6].

\section{Tumor macrostructural characteristics on imaging}

Tumors are heterogeneous in nature and during malignant transformation, their structural features change substantially at different levels. Morphologic and structural differences between tumors are sometimes apparent and classical subjective descriptors of these characteristics (e.g., spiculated margin) are common. Tumor size and volume are usually important features in tumor evaluation and may have prognostic value. However, different imaging techniques may improve the assessment of tumor structure.

\section{Tumor morphology}

The morphologic phenotype of neoplasms is widely variable; however, the presence of morphological features typical of benign, borderline, or malignant tumors increased the level of diagnostic confidence of radiologists. In this setting, different imaging-based classification systems (reporting and data system or -RADS) have been established to standardize imaging reporting and data collection in different organs, such as breast (BI-RADS), liver (LI-RADS), lung (Lu-RADS), thyroid (TI-RADS), etc. [7-10]. These -RADS lexicons include different morphological features (margin, shape, size, internal pattern, etc.) and provide an estimated risk of malignancy. So, well-defined tumor margins are considered an indicator of less infiltrative behavior and, thus, lower aggressiveness. Besides, a tumor morphologic phenotype may be associated to a pathologic entity. For instance, cystic change in renal cell carcinoma (RCC) has been mostly strongly associated with the clear cell subtype and most recent data indicate an overall favorable prognosis for the broad spectrum of predominantly cystic RCCs [11]. Finally, imaging features may be also associated to specific mutations. In the case of clear cell RCC, well-defined tumor margins were significantly more common among clear cell RCCs with loss of von Hippel Lindau (VHL) gene function [12]. The improvements in the computing capabilities of radiologic equipment have allowed the development of volume-based tumor measurements, which have demonstrated to be more sensitive to tumor changes, more reproducible and reliable than uni- or bi- dimensional measurements [13]. Tumor volume has a prognostic value in many tumor types and may improve tumor response evaluation [14]. Finally, tumor growth pattern also seems to be a prognostic significance in terms of overall survival. For example, the presence of a fibrous capsule and the characteristics of the tumor-liver interface are prognostically relevant in colorectal liver metastases [15]. 


\section{Biophysical characteristics of tumors: stiffness and elasticity}

Solid tumors are typically stiffer than the surrounding healthy tissue. This feature is evaluated in clinical practice by palpation but elastographic imaging techniques can also assess the elastic properties and stiffness of tissues noninvasively.

Elastography provides knowledge about internal strains induced in a soft material undergoing an axial stress. There are two main imaging techniques for performing elastography: US and MRI [16, 17].

\section{Technical features}

The basic principle of elastography is to image the propagation of mechanical waves within the tissue. Stiffness, a biomechanical property of tissue, represents its ability to resist deformation when subjected to a force. Elastographic techniques evaluate these properties by a sequential process with three basic steps: (a) excitation (stress) based on the application of mechanical waves for deforming the tissue; (b) evaluating the tissue response (strain); and (c) assessment of stiffness and stiffness-related parameters displayed as quantitative parametric maps (elastograms) [16, 17]. Main elastographic techniques are based on the evaluation of the shear waves, which cause the oscillation of the particles of the medium at a right angle to the direction of propagation. Shear-wave speed is related to tissue stiffness and shows a great variation depending on the structure and state of tissue. Shear waves travel faster in stiff (tumor, inflamed, or fibrotic) tissues and slower in soft (normal or fatty) tissues. Recently, a quantitative estimation of tissue stiffness without using mechanical vibrations ("virtual" elastography) has been reported. This approach is based on the intravoxel incoherent motion (IVIM) contrast, which can be converted quantitatively into shear modulus [18].

\section{Biological bases of elastography}

Cancer alters tissue mechanical properties. Solid tumors are typically stiffer than the surrounding healthy tissue. Several tumor characteristics may explain this feature, including high cellularity, increased tumor stroma, and increased interstitial pressure [17].

\section{Interpretation guidelines}

The results of an elastographic exam are usually displayed by an elastogram, including an image representing the stiffnesses of the tissues superimposing on a cross-sectional slice of the anatomy. Interpretation of acquired images is based on different method of analysis $[16,17]$ : (1) qualitative analysis including lesion comparison to a surrounding "normal" tissue as a reference, (2) semiquantitative methods based on strain ratios between different tissues included within the selected region of interest (ROI), and (3) quantitative parameters with parametric maps.

\section{Clinical value}

Sonoelastography enables a more accurate evaluation of the nature of superficial lesions situated in breast, thyroid, testicles, or lymph nodes (LNs). Elastography can be also performed under endoscopic ultrasound (EUS) guidance (Fig. 2). Main current clinical indications of EUS elastography are solid pancreatic lesions, submucosal gastrointestinal masses, and LNs. EUS elastography is a reliable technique for the differentiation of solid pancreatic masses with a sensitivity of $95-97 \%$ and a specificity of $67-76 \%$, respectively [19]. In the case of the accuracy of EUS-guided elastography for the differential diagnosis of benign and malignant LNs, $\mathrm{Xu}$ et al. found a sensitivity of $88 \%$ and a specificity of $85 \%$ [20]. Emerging applications of EUs include prostate cancer $(\mathrm{PCa})$ and rectal tumors. Elastography has been demonstrated to be superior to transrectal EUS alone in $\mathrm{PCa}$, improving the specificity of prostate biopsies.

On its part, MRE has been tested in different tumor locations, including breast, prostate, liver, pancreas, or brain suggesting that this technique may improve tumor detection and characterization [17]. Preliminary studies with different therapies have showed an early decrease in tumor stiffness and viscoelasticity (with no change in tumor apparent tumor diffusion coefficient $[A D C]$ ), following treatment, suggesting that MRE may be more sensitive than DWI to early tumor response to therapy [17].

\section{Tumor microstructure and composition on imaging}

Clinical imaging may provide information about microstructure, organization, composition, and histological features in tumors [21-26]. Different imaging techniques may be useful for this, including diffusion and relaxation-weighted MRI, magnetization transfer (MT) techniques, and spectral CT.

\section{Diffusion-weighted imaging}

Diffusion is a fundamental imaging technique that allows a noninvasive assessment of tissue microstructure [21, $24,25,27-34]$.

\section{Technical features}

The extent of water molecule motion in tissues can be imaged by applying balanced gradients placed symmetrically about a fat-suppressed T2-weighted sequence. The weighting of the applied diffusion gradients is indicated by their $b$ value (measured in $\mathrm{s} / \mathrm{mm}^{2}$ ), which depends on the amplitude and duration of the gradients and the time between them. In the absence of water molecules 


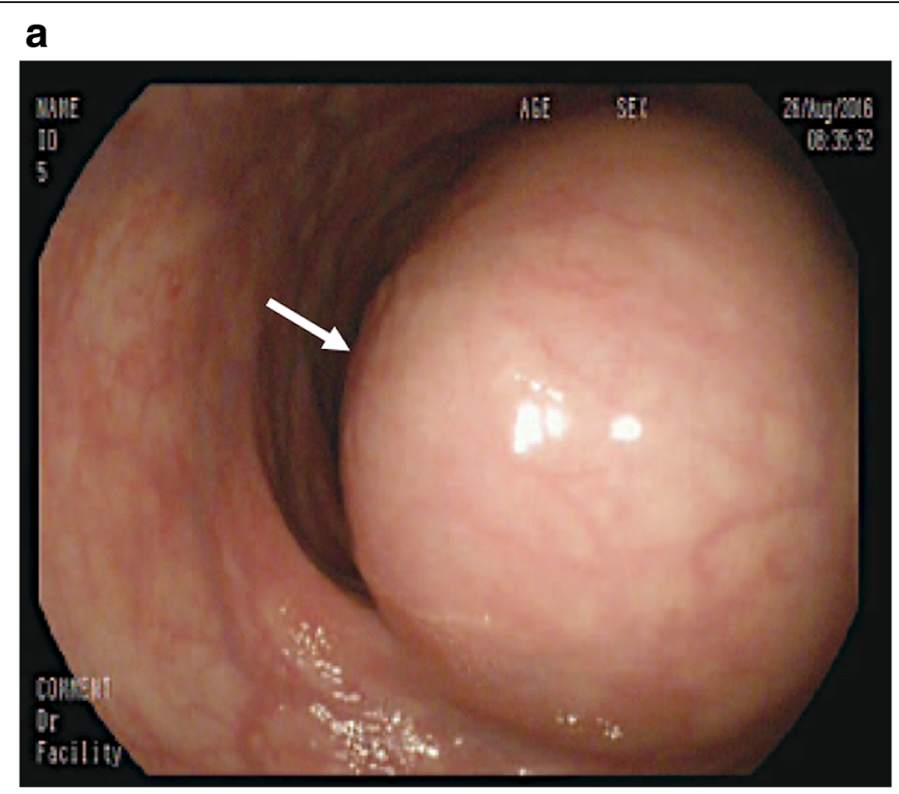

b

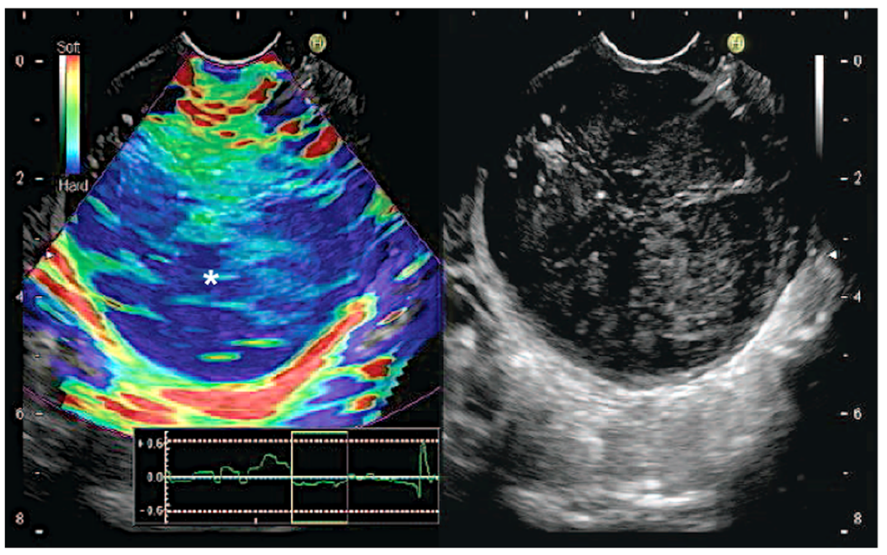

C

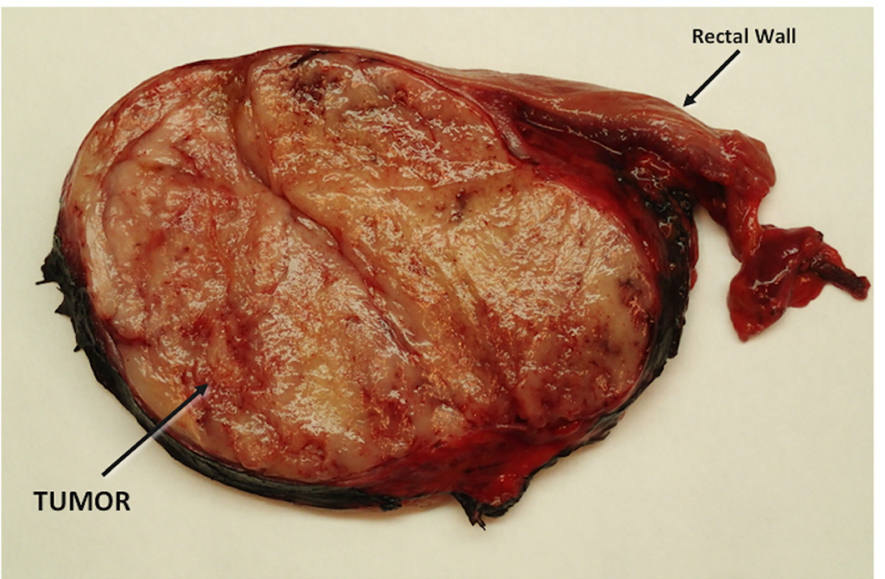

Fig. 2 (See legend on next page.) 
(See figure on previous page.)

Fig. 2 Rectal gastrointestinal stromal tumor (GIST) (white asterisk) in a 68-year-old man. a Optical colonoscopic image showed a rectal tumor (arrow). b Endorectal ultrasonographic (US) image (right) with strain elastogram (left) showed that tumor (asterisk) appeared harder (more blue) than the reference tissue on the elastogram. c A cut surface of the surgical specimen revealed a well-defined homogeneous aspect of the submucosal mass (GIST)

motion, the phase shifts due to the two gradient pulses will cancel without a significant change in the measured signal intensity (SI). By comparison, in the case of moving water molecules, their signal will not be completely rephased by the second gradient, thus leading to a signal loss. Recent technological advances in diffusion-weighted imaging (DWI) acquisition have facilitated the acquisition of multiple $b$ values, including high $b$ values $\left(>1000 \mathrm{~s} / \mathrm{mm}^{2}\right)$, in clinical practice. Besides, non-Gaussian analytic models of DWI (IVIM, diffusion kurtosis imaging [DKI], stretched-exponential model $[\mathrm{SEM}]$ ) and vascular, extracellular, and restricted diffusion for cytometry in tumors (VERDICT) were proposed to more closely reflect the distribution of physiologic and pathologic characteristics of tissues, including cellularity, microcirculation, and heterogeneity (Fig. 3). The IVIM model assumes a bi-exponential decay of signal with increased $b$ values. At low $b$ values $\left(<200 \mathrm{~s} / \mathrm{mm}^{2}\right)$, there is a deviation from the mono-exponential decay, which is due to incoherent motions of water molecules inside the microvasculature (Fig. 4) [35, 36]. On its part, DKI model analyzes the deviation of tissue diffusion from a Gaussian pattern at ultra-high $b$ values (typically $>1000 \mathrm{~s} / \mathrm{mm}^{2}$ ) [37]. SEM evaluates the effects of sub-voxel heterogeneity in diffusion. Finally, VERDICT couples DWI to

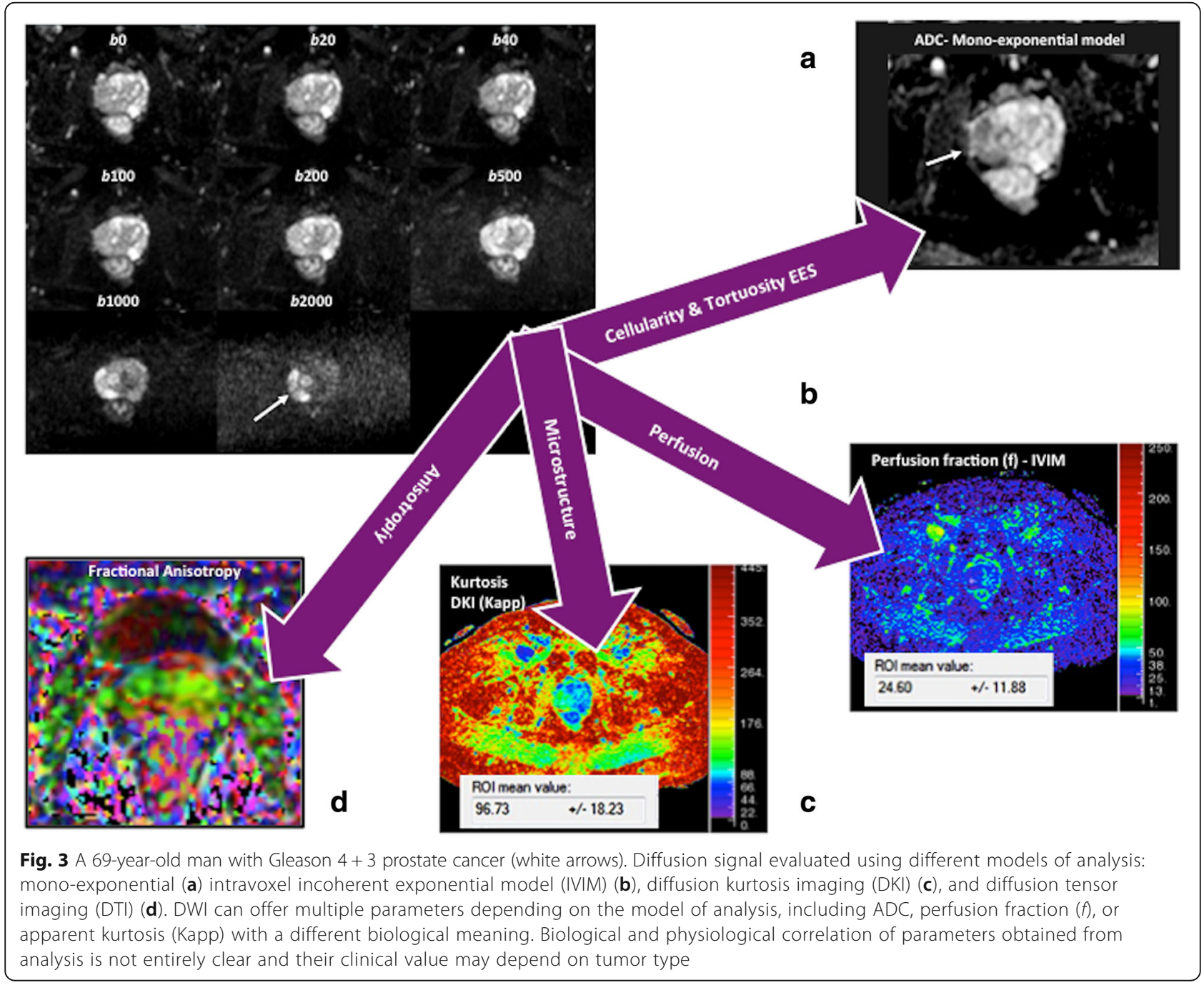




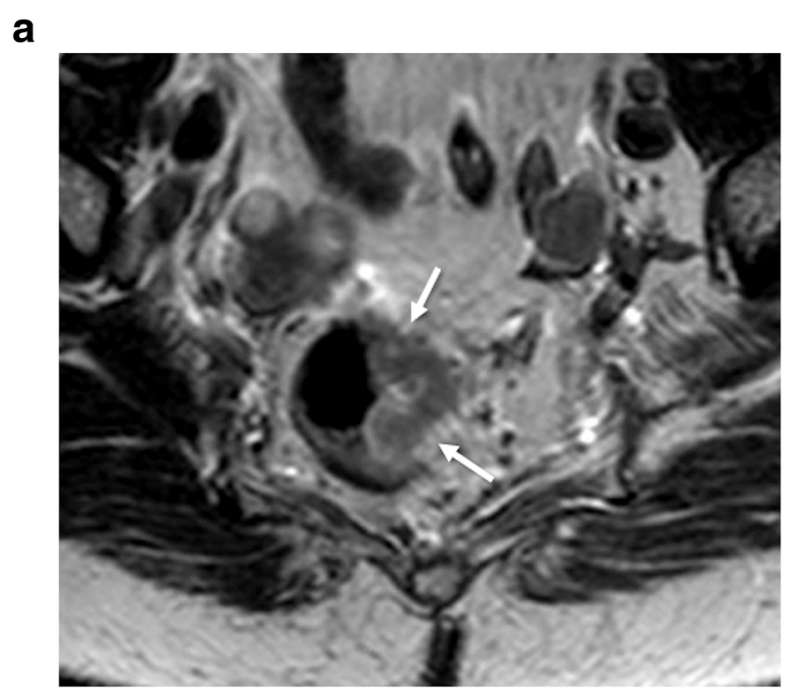

b

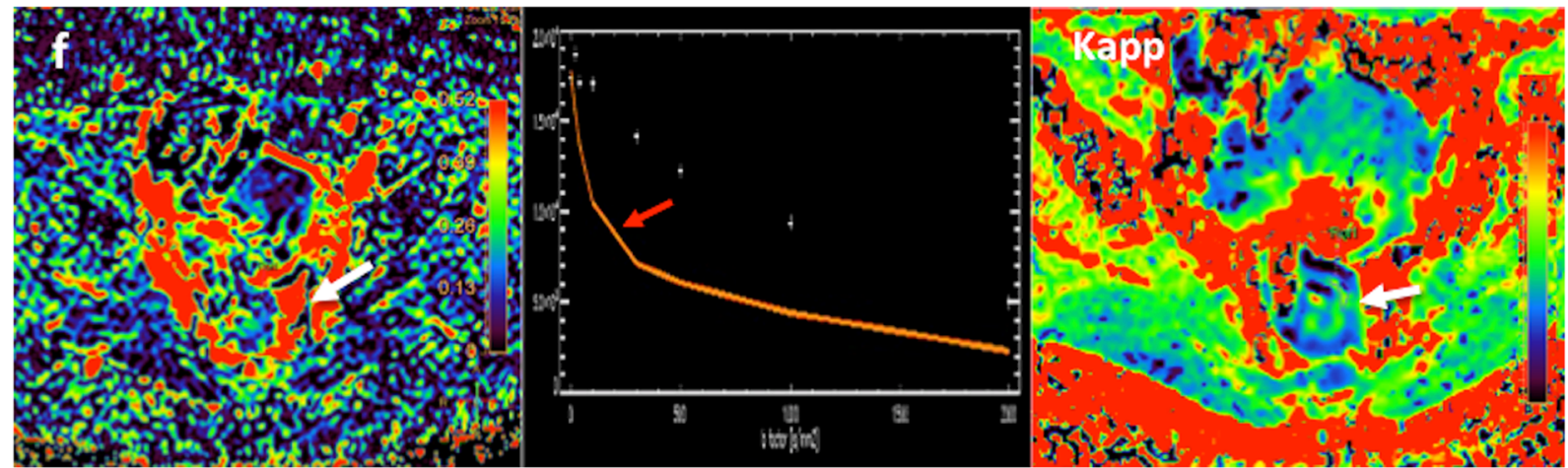

C

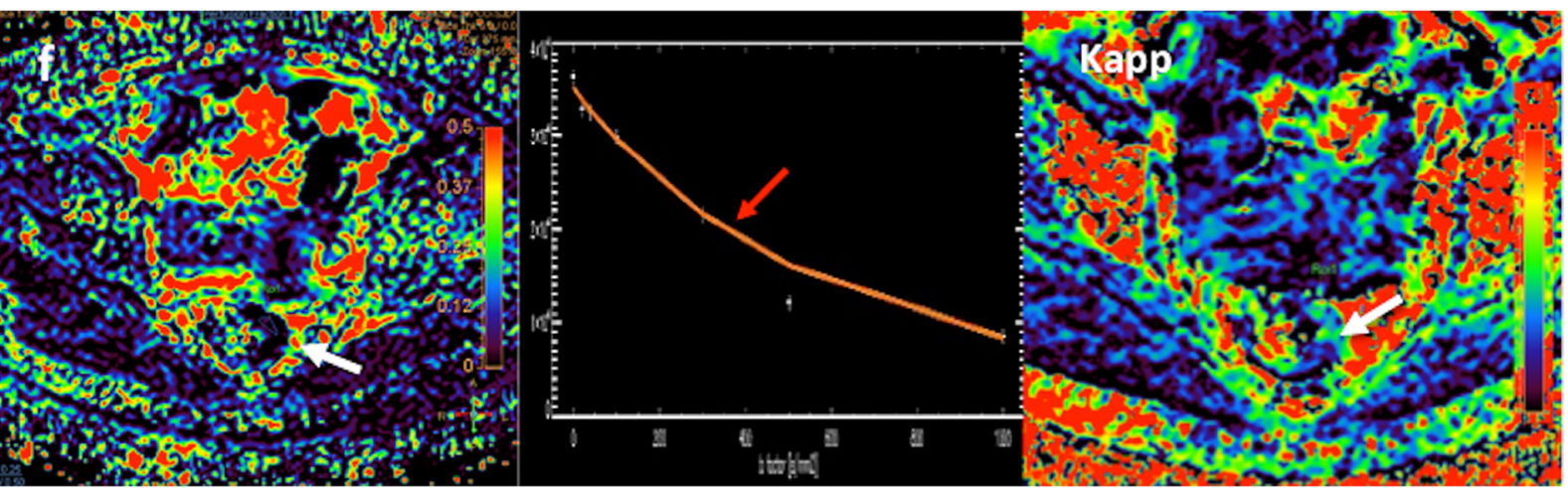

Fig. 4 Rectal cancer in a 65-year-old woman. a Axial T2-weighted image demonstrated a rectal mass deeply extending to the mesorectal fat (white arrow). b Perfusion fraction (f), apparent kurtosis diffusion (Kapp), and the curve of signal intensity decay in diffusion pretherapy. Note that this curve showed a marked attenuation of signal intensity at low $b$ values (red arrow) due to the influence of tumor perfusion on diffusion. $\mathbf{c}$ Following therapy, there are reduction of both $\mathrm{f}$ and Kapp and dissapearance of the fast attenuation of the signal intensity at low $b$ values, related to tumor response with reducer perfusion on IVIM model

a mathematical model. Prelimminary data suggest that it may allow the assessment of tumor features such as cell size, vascular volume fraction, and intra- and extracellular volume fractions $[24,25]$.

\section{Biological bases of DWI}

Diffusion measures the random (Brownian) motion of water molecules at microscopic level. However, diffusion is not free in tissues and is modified by interactions 
with cellular packing, intracellular organelles, membranes, and macromolecules and by macroscopic water movements (e.g., within blood vessels and glandular ducts). The use of DWI in tumor evaluation is based on the assumption that malignant tumors are usually more cellular and have a more complex extravascular-extracellular space than benign tumors/normal tissues, causing a lower attenuation of the signal in tumors with increased $b$ values [21, 28-31]. As a general rule, water diffusion decrease with the increased cellularity and cell size (24b). Negative correlations between the ADC values and cellularity or proliferation have been reported in many tumor types; though, there were no clear correlations in others $[32,33]$. It must be also considered that molecular mobility is anisotropic, not equal for all directions. Based on this, diffusion tensor imaging (DTI) may describe the magnitude, degree, and orientation of diffusion anisotropy and may estimate the tissular microstructure. Characterizing the non-Gaussian diffusion MRI signal behavior may also provide valuable information on tissue structure and function. IVIM model allows the separation of pure diffusion characteristics from pseudodiffusion and perfusion features. IVIM-derived parameters include the pure molecular diffusion coefficient $(D)$, the perfusion-related diffusion coefficient $\left(D^{*}\right)$, the perfusion fraction $(f)$, and the relative perfusion $\left(f D^{*}\right)$ (Fig. 4). The biological meaning of these parameters is not entirely clear. However, the $f$ values have been suggested to be related to the blood volume (BV) and have been significantly correlated with the percentage of arterial enhancement in different tumor types [34-36]. On its part, $D^{*}$ and $f D^{*}$ may hold information on blood speed and on the quantity of blood flowing through a unit tissue per unit time, respectively [34]. Most studies have also found a fair to good correlation between $f$ and histological surrogate markers of angiogenesis, such as the microvessel density (MVD), and parameters derived from perfusion imaging techniques [34-36]. DKI provides an additional model of diffusion analysis at higher $b$ values $\left(>1000 \mathrm{~s} / \mathrm{mm}^{2}\right)$, in which the signal contribution of water from the extracellular space is substantially reduced, making the diffusion measurement more sensitive to the motion of water in the intracellular compartment. However, in the case of DKI- and SEM-derived metrics (e.g., apparent kurtosis $\left[K_{\mathrm{app}}\right]$ or the stretching parameter $[\alpha])$, these parameters do not have a simple biological interpretation; although presumably may reflect tissular heterogeneity (Fig. 4) [37].
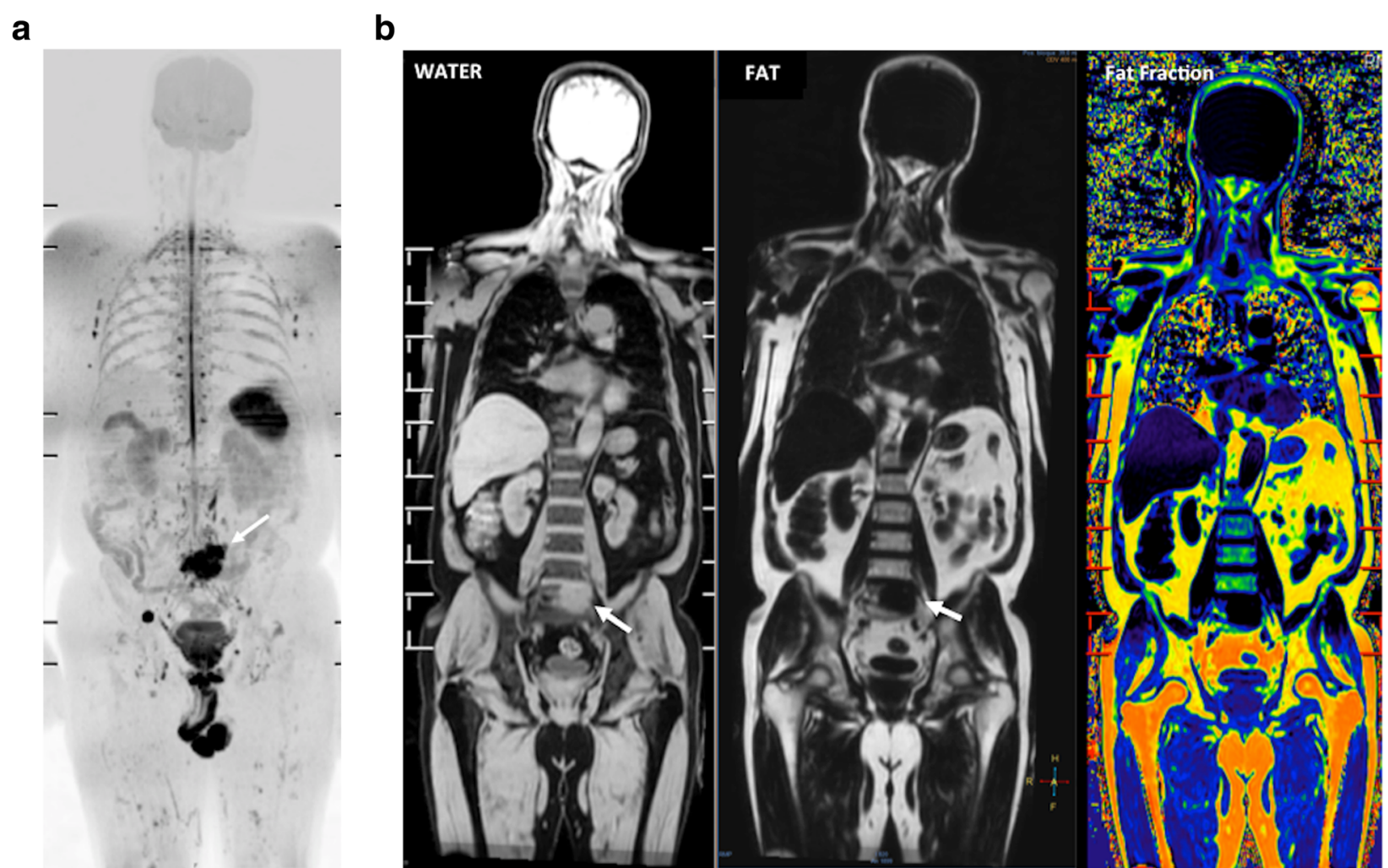

Fig. 5 A 68-year-old man with lung adenocarcinoma. a The whole-body diffusion weighted MR image $\left(b=900 \mathrm{~s} / \mathrm{mm}^{2}\right)$ depicted a metastatic deposit in the sacrum (white arrow). b Coronal reformatted T1W images obtained using the Dixon technique water only (WATER) (left), fat only (FAT) (middle), and fat-fraction in colored scale (right) evidenced not fat content and increased water in the metastatic lesion (white arrow) 


\section{Interpretation guidelines}

\section{- Qualitative evaluation}

The diffusion signal alterations serve as an excellent qualitative tool, providing an additional contrast mechanism to supplement routine conventional sequences. Areas retaining high SI on high $b$ values images suggest highly cellular tissues, such as tumors [28-31] (Fig. 5). This feature may be a useful clinical tool. A recent meta-analysis reported that visual assessment of tumor diffusion might be more accurate than ROI measurements of ADC for PCa detection [38]. However, high signal intensities on DWI are not always reliable indicators of increased cellularity, and high $b$ values images, ADC maps, and co-registered anatomical images should always be evaluated together (Table 1).

\section{- Quantitative evaluation}

The ADC has served as a quantitative biomarker for the evaluation of diffusion in clinical practice. Calculation of an ADC value is typically performed utilizing a monoexponential fit of the diffusion signal at different $b$ values. There is a linear decay of the natural logarithmic diffusion $\mathrm{SI}$ as the $b$ value is increased. The slope of this line is the

Table 1 Interpretation of tumor diffusion-weighted images

\begin{tabular}{|c|c|c|c|}
\hline $\begin{array}{l}\text { Signal intensity } \\
\text { on high b-value } \\
\text { images (b800- } \\
\text { b1000) }\end{array}$ & $\begin{array}{l}\text { Relative value on } \\
\text { apparent diffusion } \\
\text { coefficient (ADC) } \\
\text { maps }\end{array}$ & $\begin{array}{l}\text { Signal } \\
\text { intensity on } \\
\text { T2-weighted } \\
\text { images }\end{array}$ & Interpretation \\
\hline High & Low & Intermediate & $\begin{array}{l}\text { Generally, high } \\
\text { cellularity tumor } \\
\text { Coagulative } \\
\text { necrosis } \\
\text { Abscess } \\
\text { Rarely high } \\
\text { protein content }\end{array}$ \\
\hline High & High & High & $\begin{array}{l}\text { T2-shine through } \\
\text { (often } \\
\text { proteinaceous } \\
\text { fluid) }\end{array}$ \\
\hline Low & Low & Low & $\begin{array}{l}\text { Fibrous tissue } \\
\text { with low water } \\
\text { content }+/- \\
\text { viable tumor }\end{array}$ \\
\hline Low & High & High & $\begin{array}{l}\text { Fluid } \\
\text { Liquefactive } \\
\text { necrosis } \\
\text { Lower cellularity/ } \\
\text { grade tumor } \\
\text { Glandular tissue }\end{array}$ \\
\hline Low & High & High & $\begin{array}{l}\text { Vasogenic edema } \\
\text { (T2-wash out) }\end{array}$ \\
\hline Low & Low & Variable & $\begin{array}{l}\text { Hemorrhagic } \\
\text { content (T2-black } \\
\text { out) }\end{array}$ \\
\hline
\end{tabular}

ADC value (units $10^{-3} \mathrm{~mm}^{2} / \mathrm{s}$ ). Malignant lesions usually have lower $\mathrm{ADC}$ values compared to surrounding normal tissue, edema, and benign tumors [28-31]. Unfortunately, there is considerable disparity in the published ADC values across different anatomies, vendors, or technical parameters of the acquisition causing that there are no unique cut-off $\mathrm{ADC}$ values that distinguish cancer from normal tissues. Besides, both well-differentiated tumors and necrotic poorly differentiated tumors may show high $A D C$ values and some normal tissues (including endometrium, bowel mucosa, testes, and normal LNs and nerves) may show increased SI on high $b$ value [28-31]. Finally, non-Gaussian models yield several quantitative parameters that may improve diffusion assessment. Malignant lesions usually present high values of $f$ and $K_{\text {app }}$ and lower values of $\alpha[27,34,37]$.

\section{Clinical value}

DWI has shown clinical value for tumor detection, diagnosis and grading, staging, prognosis, therapy monitoring, detection of tumor relapsing, and assessment of patient's outcome [27, 31, 34, 39-44]. Malignant tumors are generally more cellular than benign tissues and show lower ADC values. However, false positive results may occur with abscesses and infective processes and false negatives may happen with cystic, necrotic lesions and in well-differentiated neoplasms (particularly adenocarcinomas) [27-30]. DWI has also demonstrated to be an effective tool for evaluating tumor response to therapies [40-44]. Successful treatment is usually reflected by increases in ADC values. However, it depends on the mechanism of action of therapy given. Transient decreases in ADC can also be observed in patients treated with anti-VEGF therapies in brain tumors [43, 44]. This finding appears to be related to cellular swelling and reductions in tumor BF, extracellular space, and vasogenic edema. Accurate imaging response evaluations of oncologic patients are sometimes notoriously difficult with conventional imaging techniques, especially in the case of bone lesions. In this setting, whole-body (WB)-DWI MRI has shown clinical value for the assessment of therapeutic response in patients with metastatic bone disease, multiple myeloma, and lymphoma [41, 43-54] (Figs. 6 and 7). Finally, regarding the prognostic/predictive value of ADC in tumor assessment, lower ADC values are usually associated to patients with poor outcome; although are correlated to a favorable response to most treatment options.

IVIM represents an alternative to perfusion contrastenhanced techniques without the use of contrast agents in oncologic imaging. IVIM-metrics (mainly $f$ ) have demonstrated to be useful for tumor diagnosis and characterization in liver, pancreatic, breast, $H \& N$, brain, renal, cervical, and rectal tumors [35, 55]. IVIM has also shown promising results for monitoring therapy response 
a

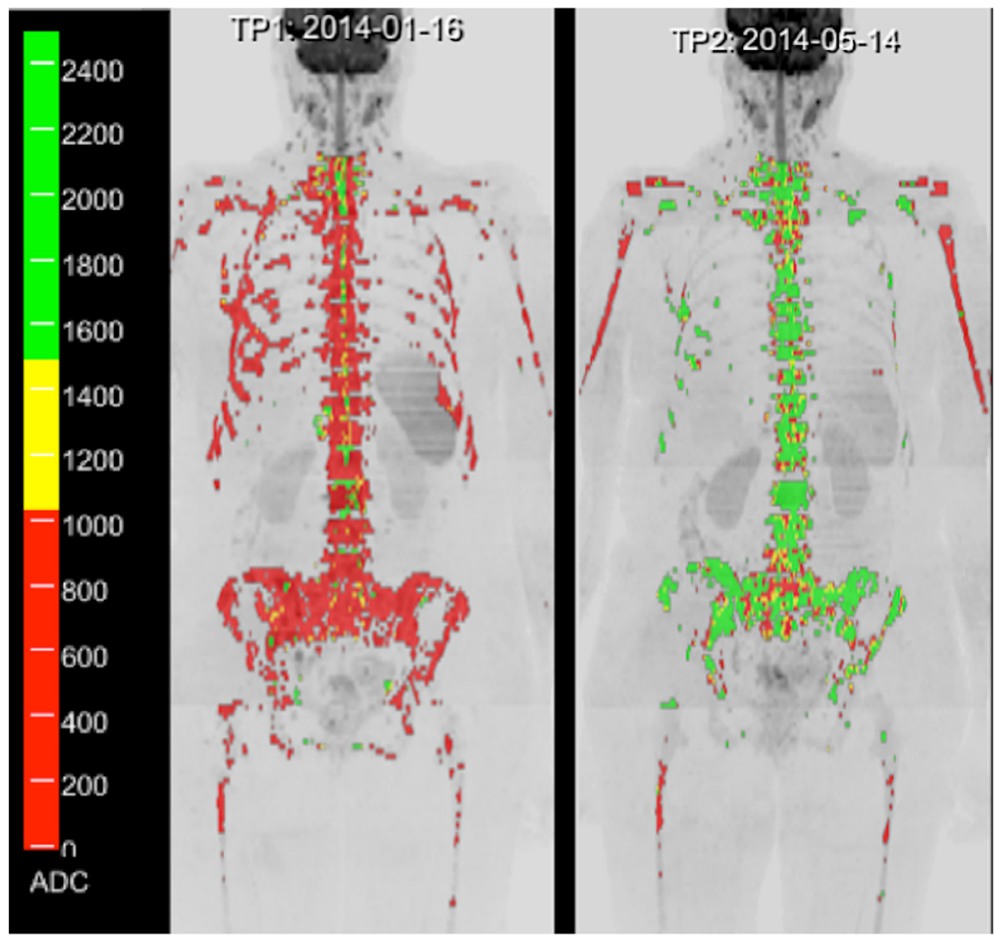

b

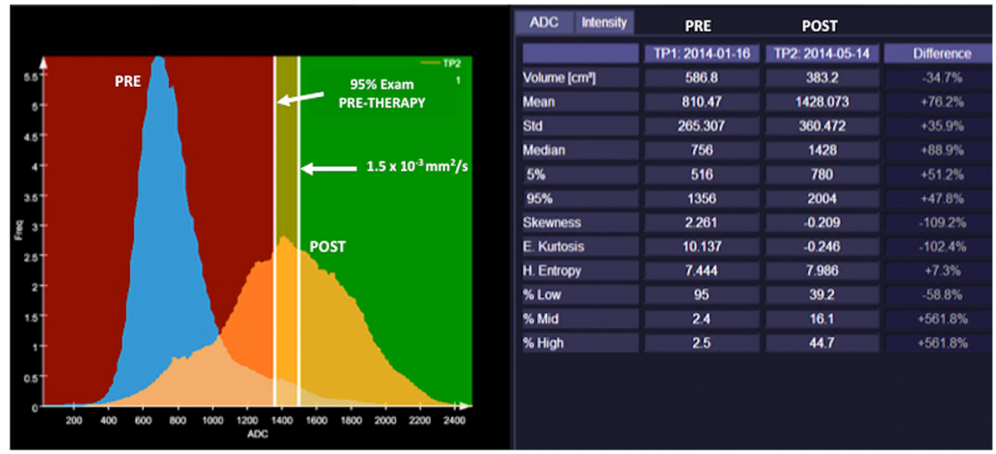

Fig. 6 A 52-year-old woman with metastatic breast cancer treated with chemotherapy (a). Whole body diffusion-weighted inverted gray-scale maximun intensity projection (MIP) of $b=900 \mathrm{~s} / \mathrm{mm}^{2}$ images superimposing the ADC values associated with each voxel in color scale before (left) and after one cycle of therapy (right). Red colored voxels represent untreated disease or those with no-detectable response. Thus, yellow voxels represent regions "likely" to be responding. Green colored voxels have ADC values $\geq 1500 \mathrm{\mu m}^{2} / \mathrm{s}$ representing voxels that are "highly likely" to be responding with tumor cell kill. Tumor evaluation showed a great change in ADC values (predominantly green voxels with $A D C$ values $\geq 1500 \mu m^{2} / s$ ) indicating tumor necrosis. $\mathbf{b}$ A detailed ADC analysis of histogram metrics evidenced a reduced tumor volume as well as improvement in several histogram metrics (mean ADC, kurtosis, etc.) that have changed significantly during treatment due to extensive necrosis (compare to Fig. 7)

(especially antiangiogenic drugs or vascular targeting agents) in clinical practice $[21,35,55]$.

Clinical applications of kurtosis have been mainly focused on prostate, breast, $\mathrm{H} \& \mathrm{~N}$, lung, renal, and brain tumors. Published data suggests that DKI may provide additional information and may improve tumor diagnosis and characterization compared with conventional diffusion parameters in these tumor types [37]. Up to now, SEM has been used in a limited way in the evaluation of tumors. Preliminary data of the use of this technique have been published in prostate, breast, cervical, rectal, ovarian, and H\&N cancers and gliomas [37].

\section{Tissular composition and imaging}

Imaging (specially MRI) may allow the depiction of tumor composition. Several tumor types show characteristic imaging findings. For instance, melanin (a paramagnetic substance) shortens the $\mathrm{T} 1$ relaxation time, making 
a

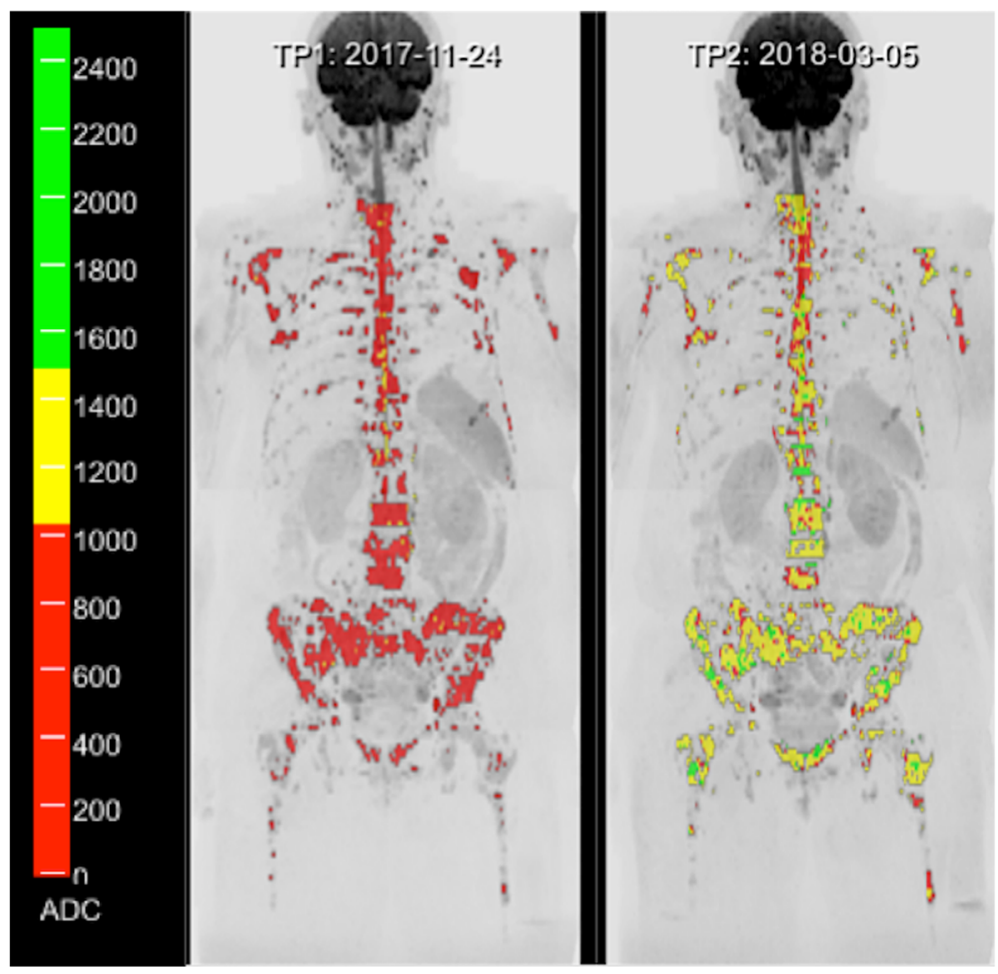

b

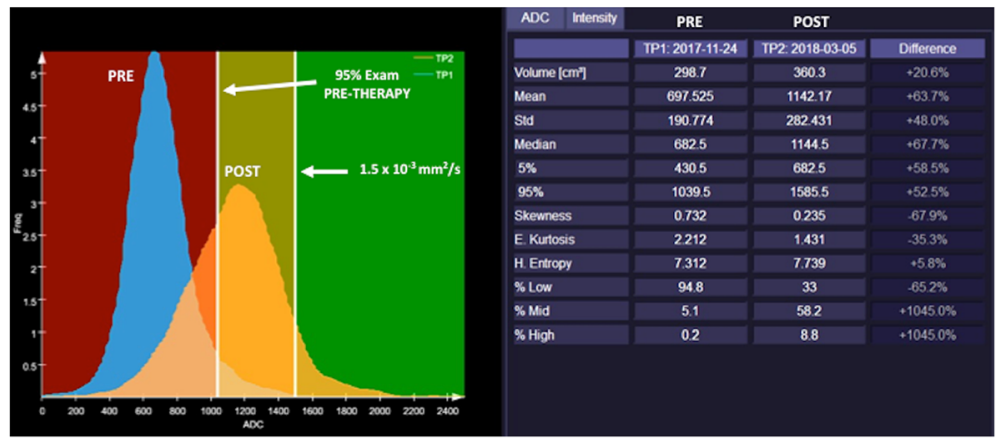

Fig. 7 A 63-year-old woman with metastatic breast cancer treated with an anti-HER2 agent and hormonotherapy. a Whole body diffusionweighted inverted gray-scale maximun intensity projection (MIP) of $b=900 \mathrm{~s} / \mathrm{mm}^{2}$ images superimposing the ADC values associated with each voxel in color scale before (left) and after one cycle of therapy (right). Red colored voxels represent untreated disease or those with no-detectable response. The yellow voxels lie between the 95 th centile value of the pre-treatment histogram and $1500 \mathrm{um}^{2} / \mathrm{s}$. Thus, yellow voxels represent regions "likely" to be responding. Green colored voxels have ADC values $\geq 1500 \mu \mathrm{m}^{2} / \mathrm{s}$ representing voxels that are "highly likely" to be responding with tumor cell kill. In this case, response assessment demonstrated a discrete change in ADC values (predominantly yellow voxels). $\mathbf{b}$ The detailed ADC analysis of histogram metrics evidenced an increased tumor volume with moderate changes in several histogram metrics (mean ADC, kurtosis, etc.) suggesting an apoptotic effect of targeted therapies (compare to Fig. 6)

melanoma appear hyperintense on T1-weighted images. MRI is a useful tool for the assessment of fat content, T1, T2, or T2* mapping, or MT. MRI fat quantification allows monitoring bone marrow (BM) composition in oncologic patients and $\mathrm{BM}$ changes that result from therapy. $\mathrm{BM}$ has variable composition and vascularization (Fig. 5). Yellow BM is primarily composed of fat $(>80 \%)$, while red normal red BM or bone tumor infiltration usually show and increased percentage of water $(30-40 \%$ water in normal red BM). These features may be useful in the evaluation of patients with metastatic bone disease for diagnosis or therapy response assessment [43, 50, 53, 56-58]. Besides, each biological tissue has a T1 and T2, or T2* relaxation times based on its cellular and interstitial 


\section{a}
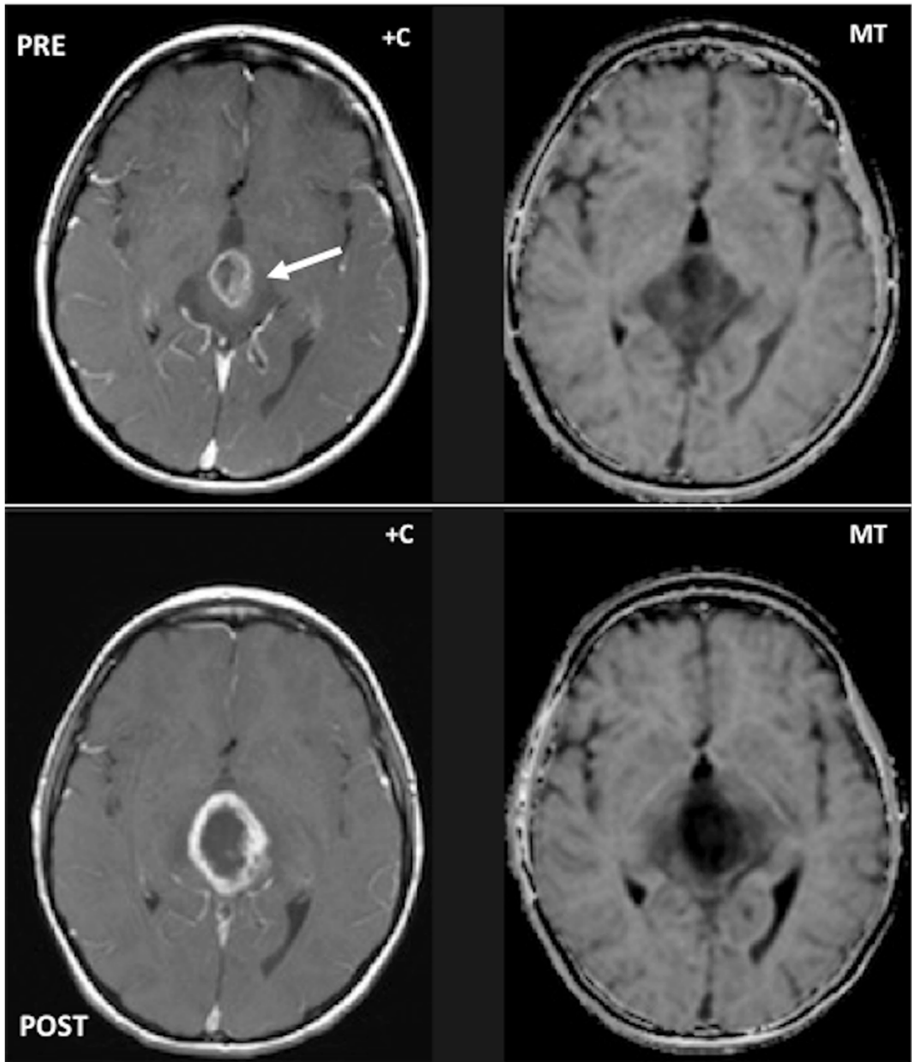

b

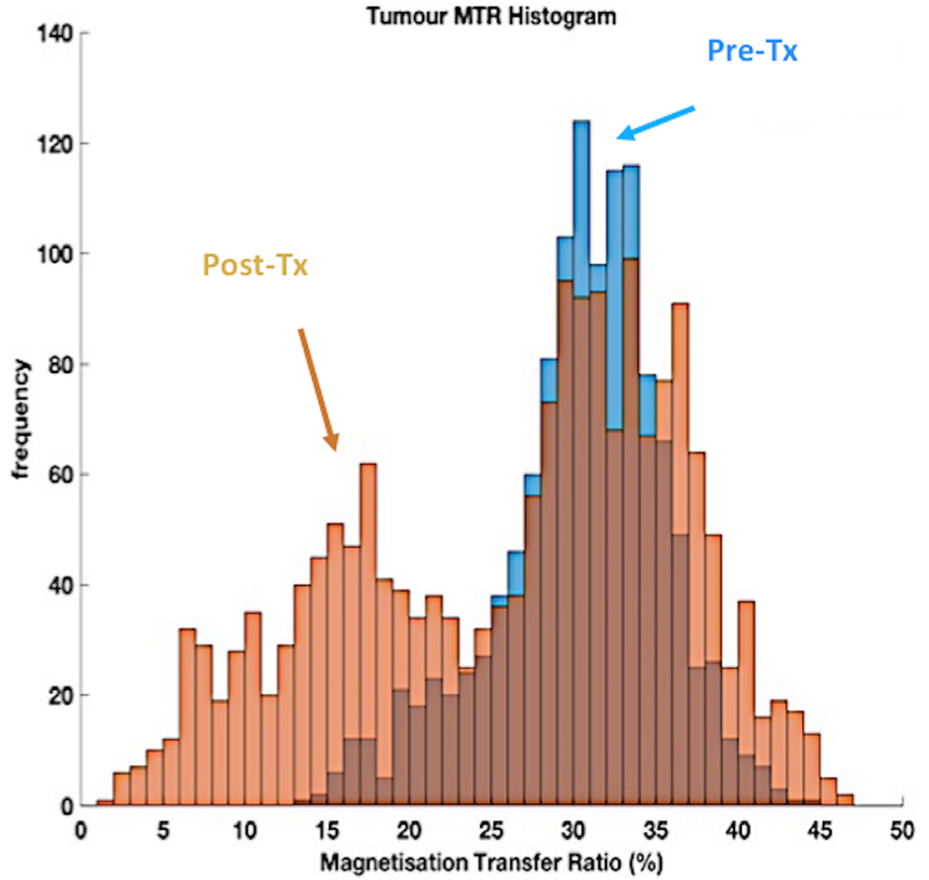

Fig. 8 (See legend on next page.) 
(See figure on previous page.)

Fig. 8 An 8-year-old patient with high-grade tectal plate glioma (white arrow). a Post-contrast T1-weighted (+C) and magnetization transfer (MT) images were obtained before (top row) and after (bottom row) chemoradiotherapy; and (b) the corresponding MT ratio histograms of lesion are as shown. The magnetization transfer acquisition comprised a set of four geometry-matched 3D-GRE scans: two flip angles ( 4 and $\left.24^{\circ}\right)$, with/ without MT pulse (1.5 kHz offset) on a 1.5 T MR system. Note the reduction in the MT ratio (histogram in $\mathbf{b}$ ) associated with response to treatment, accompanied by slight increase in size and enhancement of the tumor (a). [Images courtesy of Dr. Neil P. Jerome, Norwegian University of Science and Technology]

components. T1 mapping can detect important tissular characteristics such as excess of water (e.g., edema), protein deposition, and the presence of other T1-altering substances, such as lipid or iron (hemorrhage, siderosis). Quantitative T1 mapping requires a series of images using different inversion times to derive a $\mathrm{T} 1$ recovery curve resulting in a map that describes the relaxation value on a pixel-by-pixel basis, expressed in milliseconds. In oncology, studies about the use of $\mathrm{T} 1$ values in tumors evidenced that this parameter was greater than in normal tissues due to an increased extracellular space. On the contrary, low tumor T1 values have been correlated to increased necrosis, low water content, and high levels of proteins [59]. Native T1 mapping could also represent an in vivo biomarker for the differentiation of tumor grade [60]. Significant changes in T1 were shown in several pre-clinical models in response to therapy $[59,61]$. The use of T2 mapping in oncology has been mainly focused on PCa. Sabouri et al. have demonstrated the feasibility of T2-derived parameters (e.g., luminal water fraction) in the detection and grading of cancer [62]. T2 values were significantly lower in Gleason $\geq 7$ than in Gleason $\leq 6$ cancers in peripheral zone, but this parameter will not be sufficient by itself to adequately characterize focal abnormalities. An explanation of this feature may be the effect of normal prostate tissue interdigitated with malignant glands, which may reduce contrast between tumor and normal prostatic tissue [63]. Finally, quantitative $\mathrm{T} 2 *$ mapping seems also to be a method that may be potentially useful for characterizing malignant tumors. In this setting, $\mathrm{T} 2 *$ mapping showed greater diagnostic accuracy than ADC mapping in the characterization of intermediate- and high-grade $\mathrm{PCa}$, although it also demonstrated a limited value in the characterization of low-grade PCa [64]. In the case of breast cancer, the $\mathrm{T} 2 *$ value is significantly longer in invasive cancers compared with ductal carcinoma in situ and in high-grade tumors [65]. Unfortunately, a reliable diagnosis of malignancy cannot be made on the basis of a quantitative evaluation of $\mathrm{T} 1, \mathrm{~T} 2$, or proton density indexes.

MT imaging and chemical exchange saturation transfer (CEST) can evaluate the presence of molecules other than water. MT may be useful for evaluating tissues with significant water-macromolecule interactions. This technique has showed promising results as a possible tool for tumor assessment in prostate, testicle, rectal, breast, and brain tumors (Fig. 8) [66]. On its part, CEST is just one type of MT. CEST can detect low concentrations of molecules through the presence of ${ }^{1} \mathrm{H}$ protons that are exchangeable with those of water causing a decrease of signal intensity. Amide proton transfer (APT) imaging is the most widely used CEST technique. APT imaging for cancer assessment has been mainly focused on the brain, but higher APT values have been found in malignant tumors compared with those in normal tissues and benign lesions in brain, breast, prostate, chest, and H\&N. APT values also varied between malignant groups and tumor grades $[67,68]$.

Spectral CT also enables material identification (calcium, fat, etc.) and quantification, providing increased tumor detection and characterization [69]. In this setting, for example, Kosmala et al. reported that material-specific image processing may facilitate the identification of BM tumor infiltration [70].

\section{Tumor microenvironment}

The biology of tumors can no longer be understood simply by evaluating tumor cells but instead must include the contributions of the tumor microenvironment (TME) to tumorigenesis. TME is a complex, heterogeneous, and dominant component of solid tumors. TME includes the acellular component (named the extracellular matrix, ECM) and different co-opted cell types, including cancer-associated fibroblasts, mesenchymal cells, and immune infiltrate. The non-malignant cells of the TME can comprise $>50 \%$ of the mass of tumor burden. TME plays critical roles in both promoting the malignant progression of solid tumors and modifying the response of solid tumor cells to therapy. Pathological TME usually shows insufficient oxygenation (hypoxia) and acidosis. Multiple imaging modalities have been employed to evaluate the TME, but most of them are still at the pre-clinical phase of testing [71-73].

\section{Imaging of tumor stroma}

Apart of the study of tumor vascularization, imaging evaluation of tumor stroma has been scarce. The stroma can make up a significant proportion of a tumor volume, and differs from normal stroma, showing a high number of fibroblasts, deposition of type I collagen and fibrin, and a marked infiltration of inflammatory cells. Stroma may deeply influence imaging findings of tumors (Fig. 9). 


\section{a}

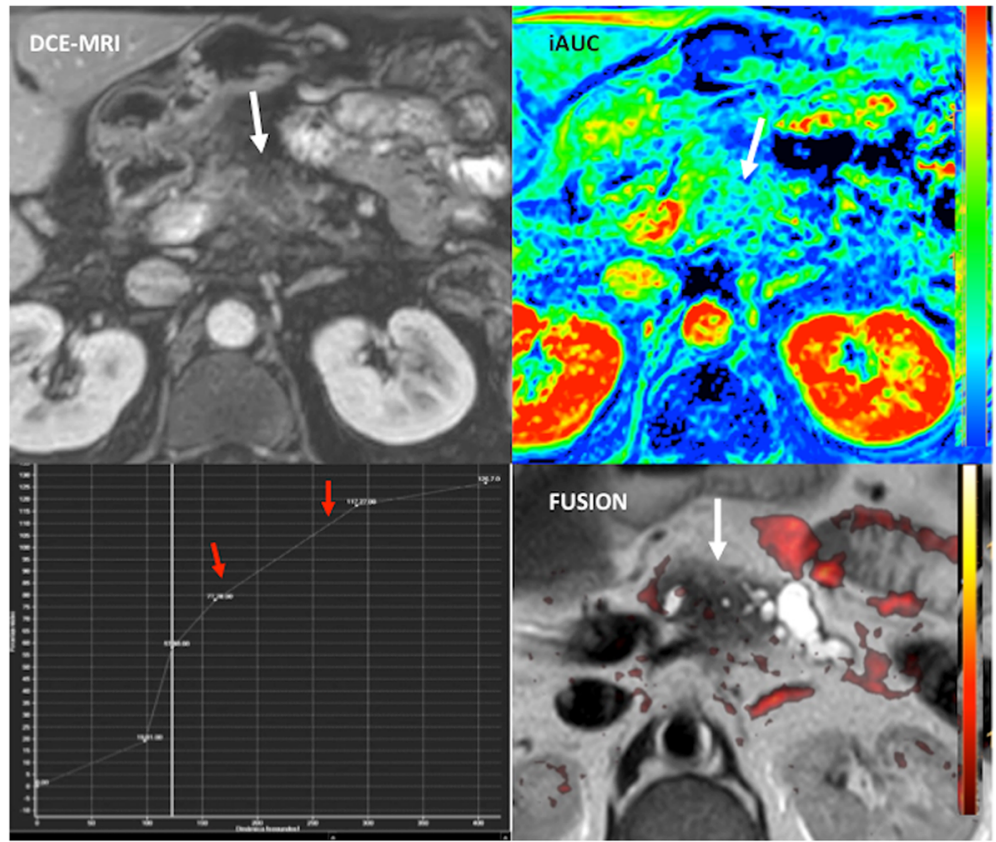

b

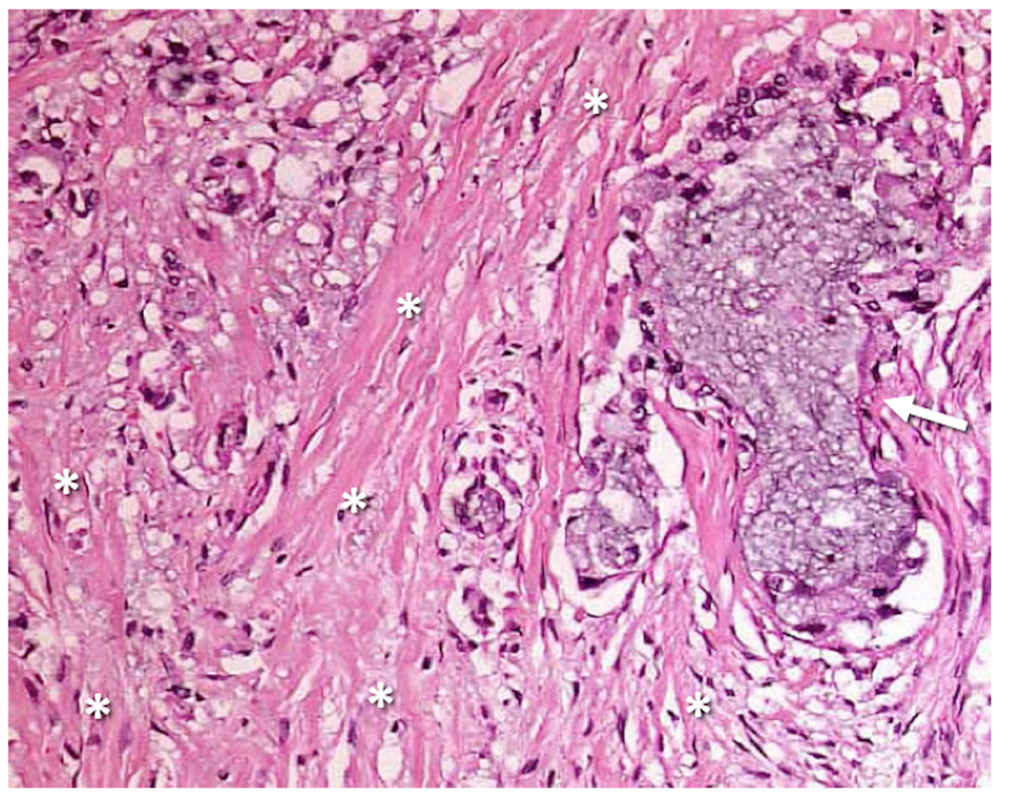

Fig. 9 Desmoplastic reaction in a 51-year-old patient with pancreatic adenocarcinoma. a Imaging evaluation including an axial fat-suppresed contrast-enhanced T1-weighted dynamic MR image (DCE-MRI, top, left), a time/signal intensity curve analysis (botton, left), a parametric map corresponding to the initial area under the curve (iAUC), and a fusion of axial T2-weighted image fused with a superimposed color-coded map derived from high $b$ value DWI (FUSION) clearly showed a hypoperfunded mass with a pattern of progressive enhancement (curve type 1, red arrows) and no restricted diffusion in the tumor in the fusion image. These findings were secondary to the predominance of fibrosis within the lesion. b Histological analysis (H\&E, $\times 20)$ confirmed an abundant tumor desmoplastic reaction (asterisks) with clusters of tumor cells (arrow)

For instance, in the case of pancreatic cancer, neoplastic cells may only represent as little as $10 \%$ of tumor volume in pancreatic adenocarcinoma, associated to the presence of abundant desmoplastic stroma. Although these tumors usually show increased angiogenesis on histological analysis, tumor imaging findings are deeply modified by stromal fibrosis, a feature which explains that pancreatic adenocarcinomas usually show a diminished enhancement in the early phase of dynamic 


\section{a}

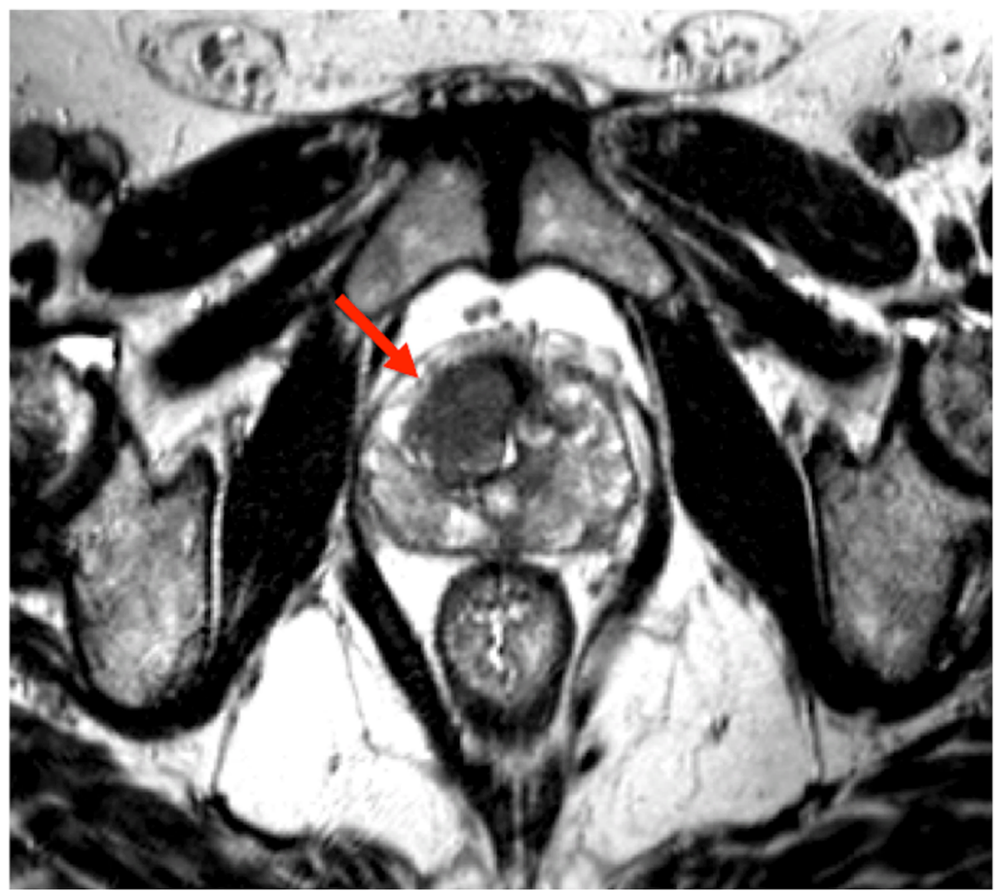

b

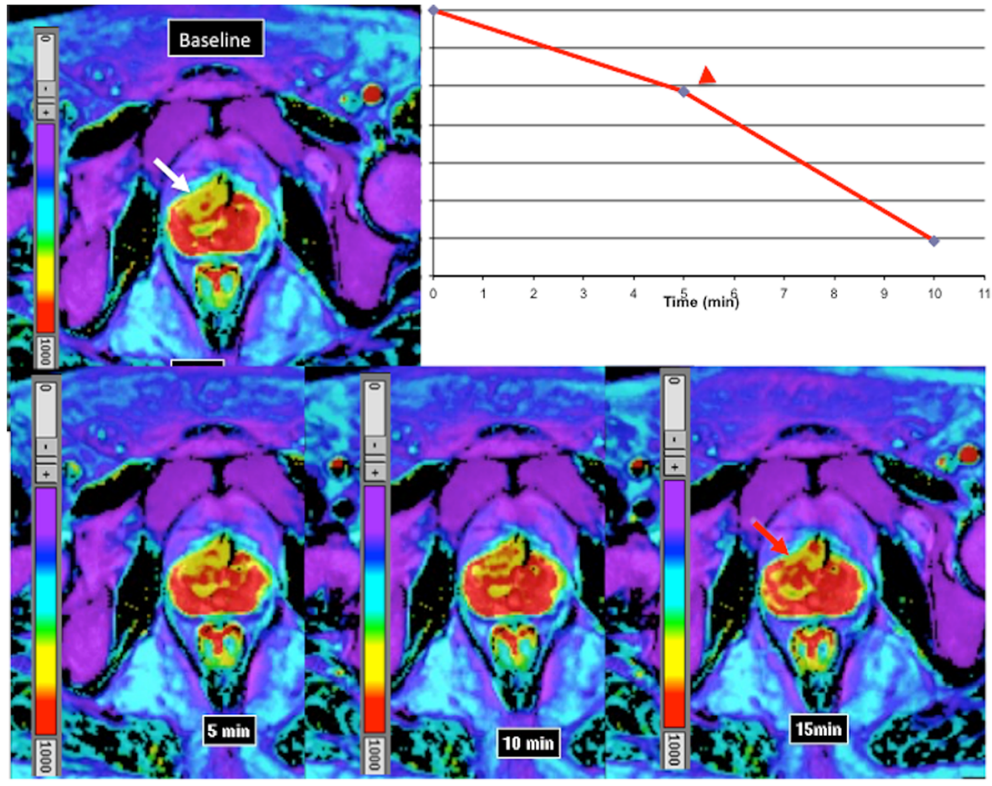

Fig. 10 BOLD sequence and tumor oxygenation. a Axial T2-weighted image in a 63-year-old man evidenced a poor defined hypointense mass in the anterior part of the transitional gland corresponding to prostate cancer (white arrow). $\mathbf{b}$ BOLD exam acquired in the axial plane at baseline and after evidenced that in baseline conditions the tumor (white arrow) showed low signal in the T2* map (high R2* values), which is related to a lower oxygenation compared to the rest of the prostate. BOLD images after 95\% oxygen breathing at 5, 10, and $15 \mathrm{~m}$ evidenced that the signal increased witihin the tumor (red arrow in the acquisition at $15 \mathrm{~min}$ ) with an inverted $\triangle R 2^{*}$ time-intensity curve (red arrowhead). These features evidence the presence of radiosensitive areas within the tumor with increasing pass of oxygen from blood to the tissue. The concentration of deoxyHb increases with rising oxygen consumption, leading to a decreasing $\mathrm{T}^{*}$ relaxation time of the surrounding tissue 
contrast-enhanced imaging techniques and gradual enhancement in the late phase (Fig. 9).

\section{Imaging of tumor-infiltrating immune cells}

Interactions between tumor cells and immune cells are involved on the initiation, progression, therapy-resistance, and prognosis of cancer. Besides, immunotherapy has successfully been introduced in the clinic for many cancer types (especially in cancer types with high mutation rates). To date, there is a limited experience with the evaluation of tumor-infiltrating immune cells and responses to immunotherapy in clinical practice and there is a lack of imaging tools to measure the behavior of immune cell populations, which is hampering the optimization and individualization of immunotherapy [74].

\section{Imaging of oxygenation and hypoxia in cancer}

Tumor hypoxia leads to treatment resistance, enhanced tumor progression, and has a negative impact on patient prognosis and survival in cancer. Hypoxia changes the pattern of gene expression resulting in a more aggressive tumor phenotype [75]. Oxygen-enhanced MRI, including blood oxygenation level dependent (BOLD) and tissue oxygen level dependent (TOLD) techniques, and PET imaging based on mitroimidazole analogues and complexes of copper with diacetyl-bis(N4-methylthiosemicarbazone) (ATSM) provide a noninvasive assessing of tumor oxygenation [75-77].

\section{Biological bases of tumor hypoxia}

Uncontrolled cell proliferation and the inability to form normal blood vessels results in impaired blood supply and low oxygen tension within tumors. Hypoxia activates adaptive cellular responses and genomic instability that contribute to tumor progression and is associated with poor prognosis and resistance to different therapies, potentially contributing to poor patient survival. Two main types of tumor hypoxia are recognized [76, 77]: (1) acute (perfusion-related) hypoxia resulting from inadequate $\mathrm{BF}$ in tumors due to structural and functional abnormalities of tumor vasculature and (2) chronic hypoxia, which is the most relevant type in oncology. Two fundamental mechanisms of chronic hypoxia can be differentiated: diffusion-limited hypoxia (caused by increased oxygen diffusion distances due to tumor growth) and hypoxia due to a compromised perfusion due to inefficient and leaky microvessels.

\section{Technical features}

- Oxygen-enhanced MRI
BOLD-MRI contrast derives from variations in the magnetic susceptibility of blood due to changes in the concentration of deoxyhemoglobin. Deoxyhemoglobin increases the transverse relaxation rate $(\mathrm{R} 2 *)$ of water in blood and surrounding tissues. This change in magnetic susceptibility produces local magnetic fields around blood vessels, changing signal intensity on MR images (Fig. 10). BOLD provides an indication of tumor blood oxygenation, but is also sensitive to vessel density, blood flow hematocrit, and pH [77]. On its part, TOLD MRI is based on T1-weighted contrast and the measured R1 $(=1 / \mathrm{T} 1)$ is also sensitive to tissue oxygenation.

\section{- Radiotracers}

${ }^{18} \mathrm{~F}$-fluoromisonidazole $\left({ }^{18} \mathrm{~F}\right.$-FMISO $)$ is the main mitroimidazole analogue and constitutes the most extensively clinically studied PET hypoxia biomarker. FMISO enters cells under hypoxic conditions and becomes trapped at rates that are inversely proportional to the local $\mathrm{pO}_{2} \cdot{ }^{18} \mathrm{~F}$-FAZA is another PET imaging tracer of tumor hypoxia that offers the advantage of higher tumor-to-reference tissue ratios in comparison with ${ }^{18} \mathrm{~F}$-FMISO.

Combinations of cooper with ATSM ligands, such as ${ }^{64} \mathrm{Cu}$-ATSM, also appear to be promising radiotracers for delineating the extent of hypoxia within tumors with PET. Under hypoxic conditions, the unstable cooperATSM complex may dissociate, causing its intracellular trapping [78].

\section{Clinical value}

BOLD images do not measure tissue $\mathrm{pO}_{2}$ directly and are more likely to reflect acute than chronic tissue hypoxia. Moreover, it is necessary to know the distribution of blood volume (BV) in tissue in order to be able to correctly interpret R2* images, thereby permitting inference of oxygenation status. However, a significant link was found between $\mathrm{R}^{*}$ and pimonidazole histology (a marker of hypoxia) in patients with $\mathrm{PCa}$ [79]. The results showed that the sensitivity of $\mathrm{R}^{*}$ in depicting tumor hypoxia was high (88\%), but its specificity was low (36\%). Concerning the role of oxygen-enhanced MRI in clinical practice, several published studies have shown a value for assessing tumor oxygenation and predict radiation response [80].

On its part, PET imaging of hypoxia has demonstrated clinical value in many different tumor types facilitating the identification of hypoxic tumor areas, predicting prognosis and response to treatment, improving radiotherapy planning, and allowing the development of hypoxia therapeutics by measuring response to hypoxia-modifying treatments. 


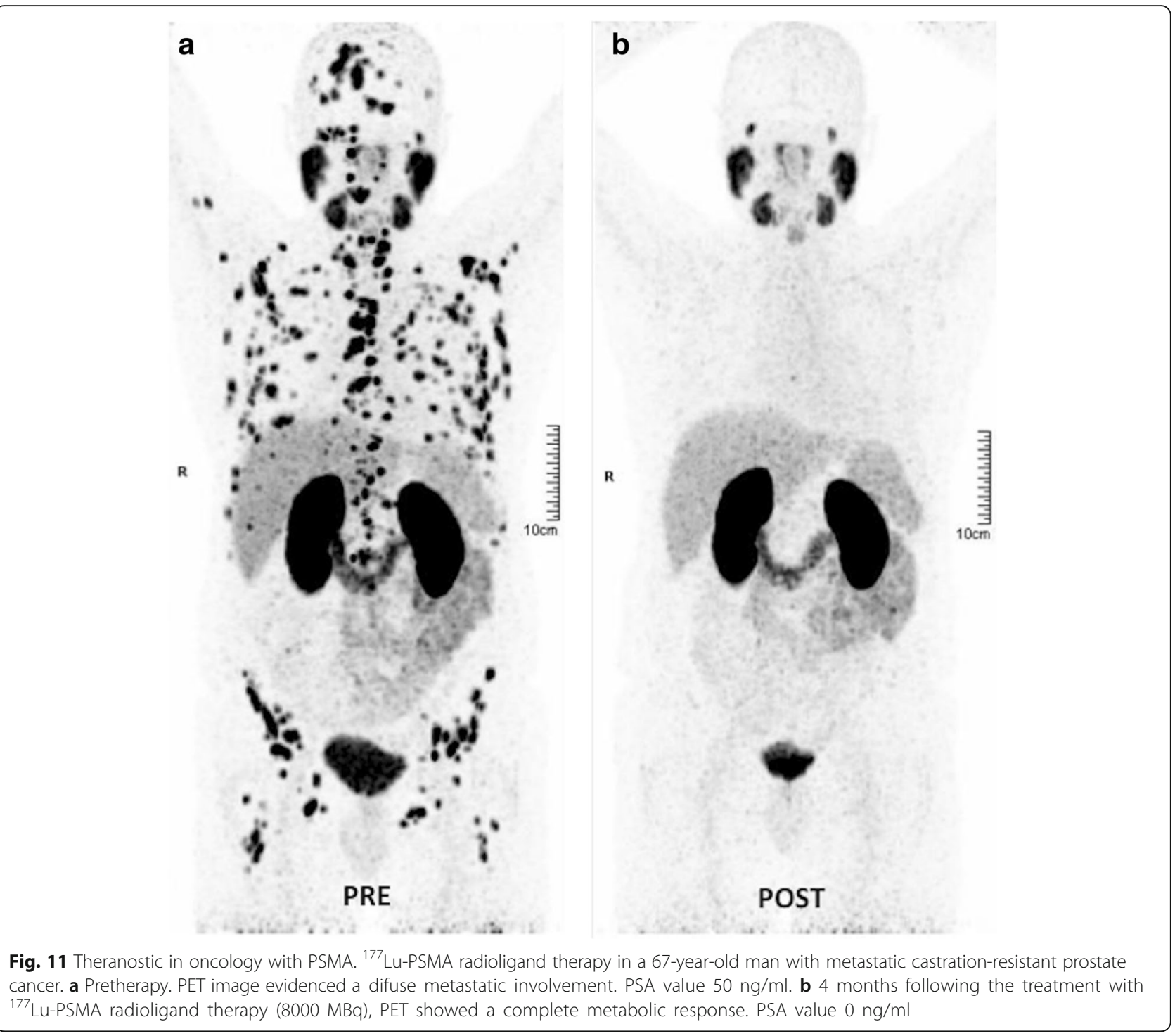

\section{Imaging of tumor $\mathrm{pH}$ (acidosis)}

Glycolytic metabolism and the hypoxic microenvironment lead to extracellular acidosis in solid tumors. Major approaches for $\mathrm{pH}$ imaging include MRS, MT methods, and $\mathrm{pH}$-dependent relaxation agents, although with a limited clinical use [81]. Published preclinical data have evidenced the presence of an acidic extracellular $\mathrm{pH}$ and alkaline intracellular $\mathrm{pH}$ in tumors relative to normal tissues [76, 82, 83].

\section{Imaging the expression of specific molecular characteristics}

Tumor cells may overexpress some specific receptors, antigens, and proteins. Specific markers such as the prostate-specific membrane antigen (PSMA) (Fig. 11), the epidermal growth factor receptors (EGFR), the human epidermal growth factor receptor-2 (HER-2), the androgen receptor, the somatostatin receptors (SSTR), the C-X-C motif chemokine receptor 4 (CXCR4), and bombesin receptors represent excellent examples of targets for cancer imaging and therapy in different tumor types [84] (Table 2).

\section{Clinical value}

An important characteristic of neuroendocrine tumors (NETs) is the expression of SSTR on their cell membranes [85]. The SSTR2, SSTR3, and SSTR5 SSTR subtypes are often overexpressed on NETs in almost $90 \%$ of cases. The determination of the status of somatostatin receptor expression is needed to select patients for peptide receptor radionuclide therapy. For a long time, ${ }^{111}$ In-octreotide (Octreoscan) has been considered the reference for imaging NETs. However, at present, ${ }^{68} \mathrm{Ga}$-DOTA-somatostatin analogues represent the "new 
Table 2 Radiotracers in the evaluation of tumor characteristics

\begin{tabular}{|c|c|c|c|}
\hline Radiotracer & Biological Correlation & Tumor Type & Main indications \\
\hline$\overline{F D G}$ & Energetic glycolytic metabolism & Many tumor types & $\begin{array}{l}\text { Diagnosis, staging, response, } \\
\text { prognostic value, relapsing tumor }\end{array}$ \\
\hline Choline radiotracers & $\begin{array}{l}\text { Cellular membrane turnover and } \\
\text { phosphatidylcholine metabolism }\end{array}$ & $\begin{array}{l}\text { Prostate } \\
\text { Bladder, Brain }\end{array}$ & Diagnosis, staging, relapsing tumor \\
\hline Methionine & $\begin{array}{l}\text { Amino acid transport and protein } \\
\text { synthesis }\end{array}$ & Brain and head and neck & $\begin{array}{l}\text { Diagnosis, grading, response, } \\
\text { prognostic value, relapsing tumor }\end{array}$ \\
\hline Acetate & $\begin{array}{l}\text { Lipid synthesis and energetic } \\
\text { metabolism }\end{array}$ & $\begin{array}{l}\text { Prostate } \\
\text { Hepatocellular carcinoma }\end{array}$ & Diagnosis, staging, relapsing tumor \\
\hline DOPA & Dopamine uptake and metabolism & Neuroendocrine tumors & Diagnosis, staging, relapsing tumor \\
\hline FLT & $\begin{array}{l}\text { Cellular proliferation and tyrosine } \\
\text { kinases-1 activity }\end{array}$ & $\begin{array}{l}\text { Lung, Lymphoma, } \\
\text { Colorectal. Gastric and } \\
\text { Pancreas }\end{array}$ & Diagnosis and tumor response \\
\hline Sigma-2 (ఠ2) Receptor & $\begin{array}{l}\sigma 2 \text { receptors are expressed in } \\
\text { proliferating tumor cells }\end{array}$ & & Diagnosis and treatment evaluation \\
\hline $\begin{array}{l}\text { Integrin targeted Imaging agents (RGD) } \\
\text { and VEGFR targeted Imaging agents }\end{array}$ & Angiogenesis & & Preclinical use \\
\hline Annexin V & Tumor Apoptosis & & Preclinical use \\
\hline $\begin{array}{l}\text { Nitroimidazoles (FAZA, FMISO) } \\
\text { Cu-ATSM }\end{array}$ & Tumor hypoxia & & Preclinical use \\
\hline \multicolumn{4}{|l|}{ Radiotracers Specific Tumor Types } \\
\hline $\begin{array}{l}\text { Radiotracers Targeting Specific Tumor } \\
\text { Markers }\end{array}$ & $\begin{array}{l}\text { EGFR expression } \\
\text { PSMA expression } \\
\text { Chemokine receptor type } 4 \text { (CXCR4) } \\
\text { DOTA-peptides (Somatostatin } \\
\text { receptors) } \\
\text { Bombesin receptors }\end{array}$ & $\begin{array}{l}\text { Lung, Colorectal } \\
\text { Prostate } \\
\text { Breast and head and neck } \\
\text { cancer metastasis } \\
\text { Neuroendocrine tumors } \\
\text { Prostate, breast, small cell } \\
\text { lung cancer, GIST }\end{array}$ & $\begin{array}{l}\text { Preclinical use } \\
\text { Relapsing tumor. Staging and } \\
\text { tumor response } \\
\text { Preclinical use } \\
\text { Diagnosis, staging, relapsing tumor, } \\
\text { response assessment }\end{array}$ \\
\hline \multicolumn{4}{|l|}{ Non-Tumoral metabolic pathways } \\
\hline $\mathrm{NaF}$ & $\begin{array}{l}\text { Bone metabolism (non-specific } \\
\text { tumor tracer) }\end{array}$ & Bone metastases & Diagnosis and staging \\
\hline
\end{tabular}

64CUATSM diacetyl-bis(N4-methylthiosemi-carbazone) copper(II)), EGFR epidermal growth factor receptor, FAZA fluoroazomycin arabinoside, FDG fluorodeoxyglucose, FLT fluorothymidine, FMISO fluoromisonidazole, GIST gastrointestinal stromal tumors, NaF sodium fluoride, PSMA prostate-specific membrane antigen, VEGFR vascular endothelial growth factor receptor

gold standard" for imaging NETs, offering high sensitivity and specificity and providing important diagnostic, therapeutic, and prognostic data. On its part, EGFR overexpression has been shown to correlate with aggressiveness of tumors and poor survival of patients in many tumor types. Imaging evaluation of EGFR expression (e.g., cetuximab DOTA-labeled PET imaging) may facilitate patient selection for HER therapy and monitor treatment response [86]. The PSMA is highly expressed on most PCa, although $5-10 \%$ of primary PCa or PCa metastatic deposits have negative PSMA results on PET. PSMA expression is usually increased in advanced stages, including metastatic castrate-resistant PCa. Unfortunately, high PSMA expression has also been described in other tumor types (colon, kidney, breast, and bladder cancer), in benign lesions (e.g., schwannomas, thyroid adenomas), and normal tissues, which may cause potential imaging pitfalls [87]. PSMA-based PET imaging may have considerable influence on the management of primary (intermediate- and high-risk) $\mathrm{PCa}$ patients as well as early recurrent disease [88]. Besides, PSMA may also represent a possible target for therapy in advanced PCa (Fig. 11). Finally, CXCR4 plays a pivotal role in tumor development and metastasis and it is overexpressed in many solid and hematologic cancers. The CXCR4 receptor also represents a promising target for imaging and radionuclide therapy [89].

\section{Imaging main tumor hallmarks}

The hallmarks of cancer (biological characteristics acquired during the initiation and progression of tumors) represent key features of tumors. Imaging techniques have unique potential to comprehend most of these tumor-related characteristics, including metabolic reprogramming, sustaining proliferative signaling and evading growth suppressors, resisting cell death and apoptosis, and inducing angiogenesis $[1,2]$. 


\section{Tumor metabolic reprogramming}

Changes in cell metabolism can contribute to malignant transformation and tumor progression. Tumor metabolic phenotypes influence tumor prognosis and treatment and can be exploited to image tumors [90]. Metabolic alterations in cancer cells include the increased generation of energy and biosynthetic intermediates needed for cell growth and proliferation. Molecular imaging techniques, which include MRSI, PET, and SPECT imaging, can assess the altered metabolic profiles of tumors [91].

\section{Molecular imaging with radiotracers}

Over the last decade, many promising tumor-specific radiotracers have been developed and evaluated for assessing tumor metabolic changes with PET and SPECT [84, 92, 93] (Table 2).

Biological bases of metabolic imaging with radiotracers - Energetic metabolism (glycolysis)

Reprogramming of the energetic metabolism is a fundamental characteristic of cancer. The first discovered metabolic phenotype was aerobic glycolysis (Warburg effect), by which energy generation shifts from oxidative phosphorylation to anaerobic glycolysis, even under normal oxygen concentrations [92]. 2-[ $\left[{ }^{18} \mathrm{~F}\right]$-fluoro-2-deoxy-D-glucose (FDG) is the radiopharmaceutical most frequently used for clinical PET imaging. FDG is a glucose analog that can be transported into cytoplasm by glucose transporters (Glut). Malignant tumors have a higher metabolic rate and generally express higher numbers of membrane Glut than normal cells. This results in increased uptake of FDG by tumor cells and forms the basis of FDG-PET imaging. In general, higher-grade and less-differentiated tumors are associated with higher uptake of FDG [84, 94-97].

\section{- Biosynthetic metabolism}

Malignant transformation is also associated with an abnormal anabolic metabolism due to the increasing growing rate. New radiopharmaceuticals have been developed that are capable of giving more specific tumor information of the changes in tumor biosynthetic metabolism, including increased cellular membrane turnover (Choline [Cho]-PET), altered amino acid and protein synthesis (methionine-PET), increased nucleotide (fluorothymidine [FLT]-PET), and lipid (acetate-PET) synthesis [84, 95] (Fig. 12). Besides, molecular imaging allows the evaluation of tumor-specific metabolic pathways, such as dopamine uptake and metabolism in NETs. All this metabolic information may lead to a better sensitivity and specificity in tumor assessment.

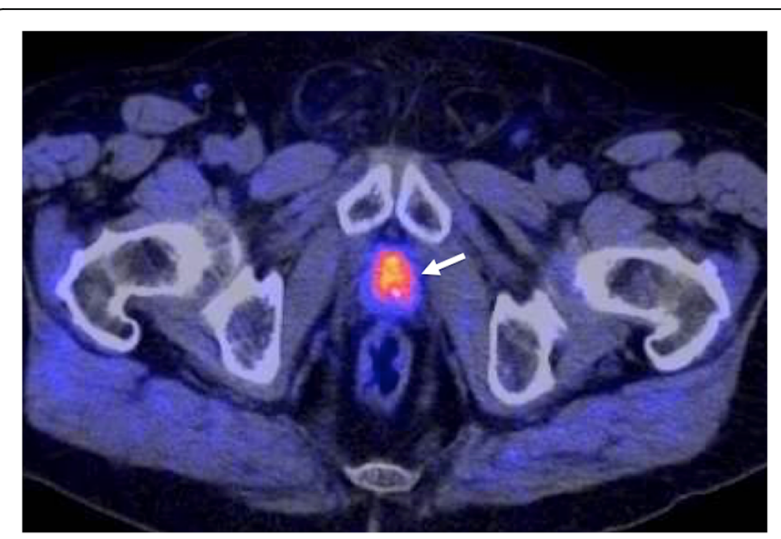

Fig. 12 An axial ${ }^{18} \mathrm{~F}$-Choline PET/CT image depicted a mass in the prostate bed (white arrow) in a 72-year-old man with a biochemical relapse of a prostate cancer following radical prostatectomy

\section{Technical features}

PET imaging is based on the injection of a radiotracer containing a positron emitter. Positrons annihilate with an electron within milliseconds of its emission, releasing two photons moving in opposite directions, which are detected during PET creating a digital image that represents the distribution of the radiotracer in the body. In the case of SPECT, the patient is injected with a radiopharmaceutical and emits radiation in the form of gamma rays, which are detected by a gamma camera. The combinations of a dedicated PET scanner and multidetector CT (PET/CT) or MRI (PET/MRI) have enabled integrated molecular, functional, and high-resolution morphologic imaging and currently play a critical role in oncology. PET/CT or PET/MRI data result in higher sensitivity and specificity of cancer assessment compared to PET alone. Combined PET/MRI brings the inherent advantages of MRI, including lack of ionizing radiation exposure, increased soft tissue contrast, and the possibility of a multiparametric imaging based on the combination of MR-based imaging techniques.

\section{Interpretation guidelines}

Visual interpretation of radiotracer uptake is the basis of the clinical report in PET/SPECT imaging. Absolute quantification would require complex dynamic protocols and repeated measurement of activity concentrations in arterial blood. Thus, normalization approaches have been included in clinical practice. Normalization is based on the measured radiotracer concentration with regard to the injected activity per weight, which results in a semiquantitative index, called standardized uptake value (SUV) (Fig. 13). Qualitative scales have been also used in clinical practice. Lesion uptake is compared with the uptake of a reference tissue uptake (e.g., mediastinum or liver), such in the Deauville five-point scale of lymphomas [96]. 

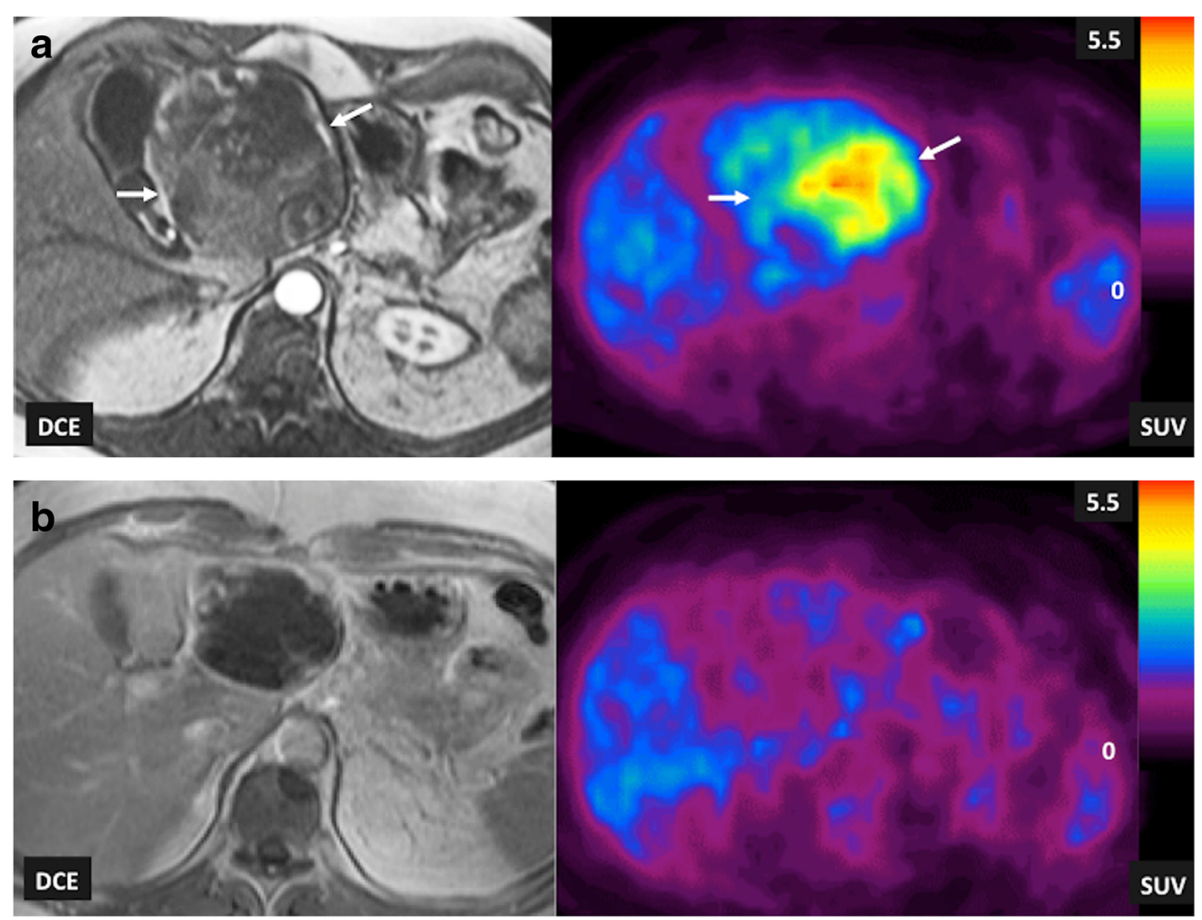

Fig. 13 Liver metastasis of a gastrointestinal stromal tumor (GIST) in a 68-year-old man. T1-weighted contrast-enhanced MRI (DCE) images and FDG-PET SUV parametric maps (SUV) acquired pretherapy (a) and following the administration of imatinib (b) and pretherapy (a), imaging findings evidenced a metabolic active tumor with areas of heterogenic enhancement (white arrows). Post-therapy (b), the tumor presented almost a total absence of enhancement and a complete metabolic response on PET imaging

\section{Clinical value}

SPECT and PET have been used for the evaluation of molecular processes in cancer patients. SPECT technology had greater accessibility, lower cost, and availability of a wider range of approved radiotracers. However, PET currently has substituted many existing SPECT oncologic applications due to its superior resolution, speed, and quantitative capability $[98,99]$.

\section{- FDG-PET imaging}

FDG is currently the most used radiotracer in clinical practice. A review of the literature established an average FDG-PET sensitivity of $84 \%$ and specificity of $88 \%$ across all oncology applications [100]. Besides, reported frequencies of change of patients' management based on PET findings ranged from 30 to $40 \%$ in the literature. PET was associated commonly with the demonstration of greater cancer burden or more anatomic sites involved $[101,102]$ and the metabolic tumor volume, which combines the dual characteristics of three-dimensional volumetric data and the metabolic activity of tumor based on FDG uptake, has been shown to be a predictor of patient outcome in human solid tumors [103]. Main clinical indications of FDG-PET/CT in oncology include (a) biopsy guidance, (b) evaluating the extent of disease in known malignancies (staging/restaging), (c) therapy planning, (d) predicting pre- and intra-treatment cancer treatment outcomes, (e) establishing tumor prognosis, (f) evaluating tumor response to therapy (Fig. 13), and (g) follow-up to detect cancer recurrence (especially in asymptomatic patients with rising tumor marker levels and those with negative or equivocal conventional imaging findings) [100-102]. Although PET/CT is not frequently used in the setting of tumor diagnosis, differentiating benign from malignant lesions (e.g., in the case of single pulmonary nodules) and searching for an unknown primary are also recognized clinical uses of FDG-PET imaging.

New technologies such as dedicated PET imaging devices and PET/MRI technology have been developed to improve cancer imaging. Dedicated PET has been mainly used in breast cancer and brain imaging. Mammography with molecular imaging PET (MAMMI-PET) is a system for dedicated hanging-breast imaging without compression. MAMMI-PET offers higher sensitivity for primary breast cancer lesions comparing to conventional PET/CT [104] (Fig. 14). On its part, PET/MRI technology is being used in those clinical scenarios in which sequential PET and MRI are the standard of care, particularly in brain, liver, bone, or pelvic imaging, but also in children or in those patients undergoing repeated imaging for whom cumulative 

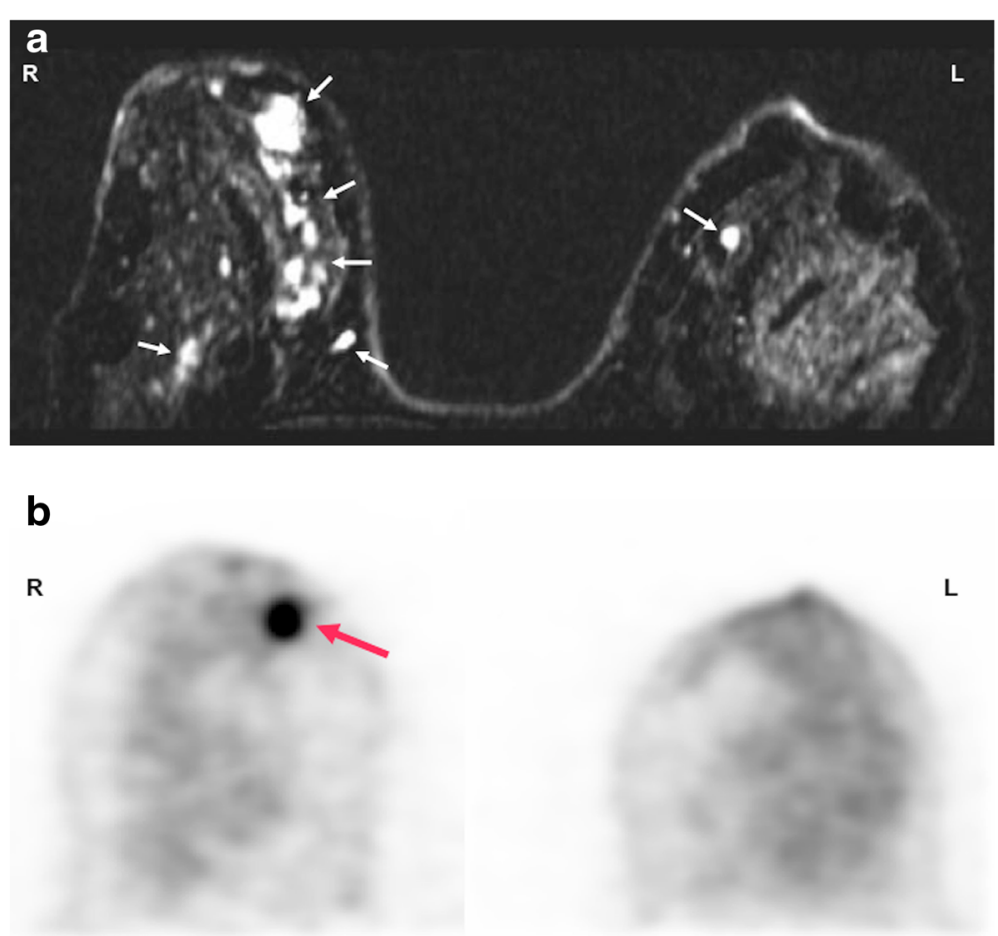

Fig. 14 A 48-year-old woman with breast cancer. a Axial contrast-enhanced T1-weighted MR image of breasts performed during last week of menstrual cycle showed bilateral multiple nodular areas of enhancement in both mammary glands (white and red arrows). b A dedicated FDGPET exam only depicted a nodular mass (red arrow) with increased FDG uptake in the right breast, corresponding to a invasive ductal carcinoma

radiation dose must be kept as low as reasonably achievable and in whole-body staging. However, robust studies demonstrating utility in clinical practice are needed [105-107].

Finally, it is necessary to consider that the value of FDG-imaging in oncology depends on several factors, such as the specific tumor type or the anatomic are of interested. FDG-PET presents recognized limitations, including (a) low sensitivity in well-differentiated/low-grade cancers, tumors with relatively low glucose metabolism (e.g., non-FDG-avid lymphomas, RCC, and bronchoalveolar cell carcinoma), hypocellular cancers (such as mucinous tumors), and tumors with low expression of Glut-1 such as PCa; (b) false positive uptake in benign processes (infection and inflammatory lesions); and (c) increased FDG accumulation in some normal tissues (brown fat) and metabolically active organs (e.g., heart and brain) [91, 99-102].

\section{- Non-FDG PET imaging}

Apart of FDG-PET imaging, various other new tracers are gaining a remarkable place in clinical practice for cancer imaging [84, 94]. Malignant transformation is associated with an abnormal Cho (an essential component of phospholipids and cell membranes) metabolism based on both the increasing growing rate and on the upregulation of Cho kinase. The use Cho labeled with ${ }^{11} \mathrm{C}$ or ${ }^{18} \mathrm{~F}$ is mainly focused on the restaging of patients with biochemical failure of PCa. However, the detection rate of Cho-PET varies depending on the site of recurrence, prostate-specific antigen levels, and the presence of hypoxia (which decrease the uptake of Cho-labeled radiotracers). On the other side, ${ }^{11} \mathrm{C}$-methionine may reflect amino acid transport and protein metabolism. This tracer has a main advantage in brain tumor imaging compared with FDG, because there is almost no tracer uptake in normal brain tissue (Fig. 15). ${ }^{11} \mathrm{C}$-acetate is an indirect biomarker of fatty acid synthesis, which is also upregulated in several tumors. In clinical practice, acetate-PET has a major application in imaging tumors in which FDG-PET is of limited use, such as PCa, renal cancer, and hepatocellular carcinoma. Finally, NETs have distinctive biochemical features based on an increased dopamine metabolism, which allow the possibility to image and treat these tumors with specific radioligands [85].

\section{MR spectroscopy}

MRS and MRSI enable in vivo measurements of a complete spectrum of metabolites that are present at millimolar concentration. 

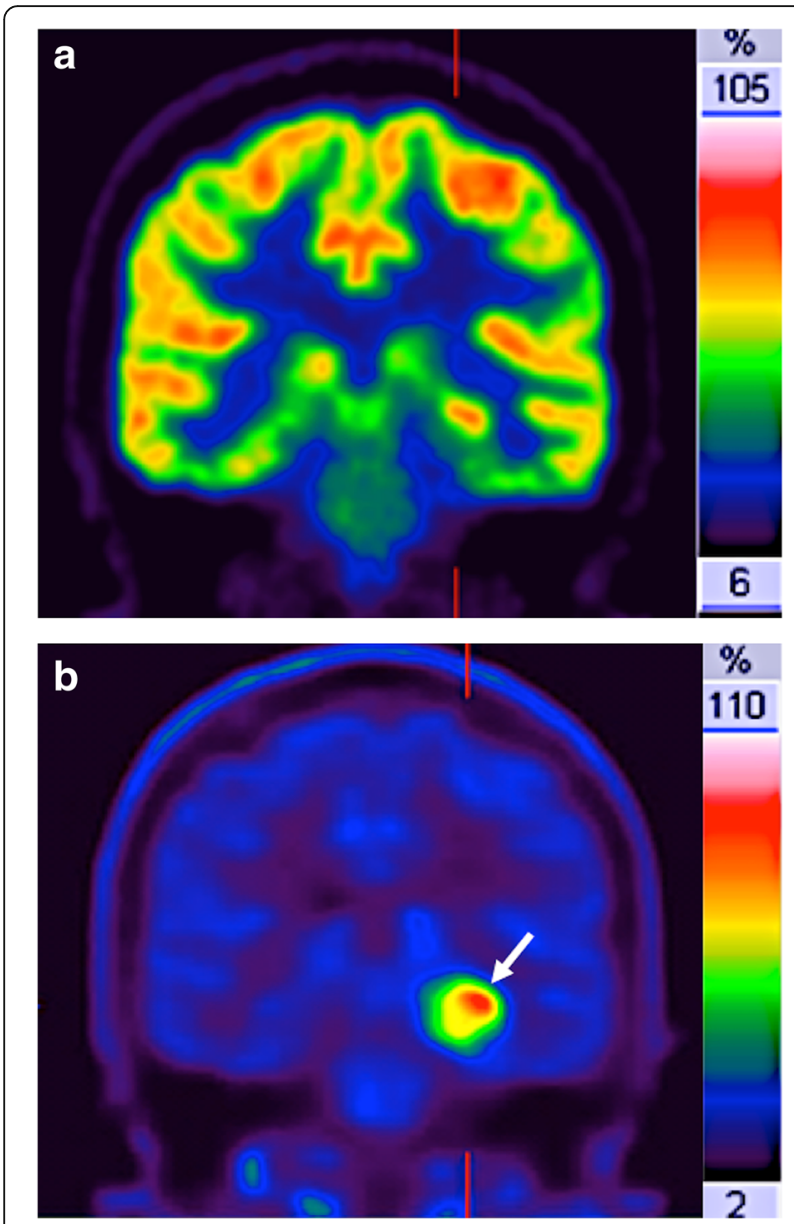

Fig. 15 Relapsing brain astrocitoma (white arrow) in a 54year-old-man. $\mathbf{a}^{18} \mathrm{~F}-\mathrm{FDG}$ and $\mathbf{b}{ }^{11} \mathrm{C}$-methionine coronal-reformatted images. Normal uptake of FDG in brain impeded an adequate tumor detection and delineation. However, ${ }^{11} \mathrm{C}$-methionine PET clearly depicted the tumor (white arrow)

\section{Molecular and biochemical bases of cancer evaluation with MRS/MRSI}

Cancers usually display altered peaks of different biological-meaning metabolites, including Cho, creatine $(\mathrm{Cr})$, lactate (Lac), lipids (Lip), citrate $(\mathrm{Ci})$, etc. The diagnostic importance of a metabolite is depending on the type of tumor and on the organ/anatomical area to be studied $[108,109]$ (Table 3).

\section{Technical features}

Spectroscopy uses the free induction decay (FID) following a radiofrequency to obtain metabolite information. One-dimensional Fourier transforms of the FID gives spectra with peaks, whose areas are proportional to the abundance of metabolites. MRS provides information about the chemical environment of the nuclear spin, which depends on the neighboring nuclei and overall chemical structure. This chemical environment changes the B0 magnetic field to which this nucleus would normally be exposed in the magnet, and these resonance frequency differences (chemical shift) allow that metabolites can be distinguished from each other. Every molecule exhibits its own "fingerprint" on the chemical shift spectrum. The exact chemical shift of a metabolite (expressed in parts per million, ppm) is independent of the applied field strength and characteristic of that nucleus, aiding accurate peak identification. Clinical MRS mainly uses endogenous signals from ${ }^{1} \mathrm{H}$ or ${ }^{31} \mathrm{P} .{ }^{1} \mathrm{H}$-MRS is the most commonly used technique because it produces the strongest signals (due to its abundance). On its part, ${ }^{31} \mathrm{P}$ MRS can measure the relative intracellular concentrations of several phosphorus metabolites. However, it is technically more complex and requires special hardware. Spectroscopic measurements generally give a static picture of tumor metabolism. In contrast, hyperpolarized MRSI offers a dynamic evaluation of tissue metabolism. Hyperpolarized MRSI increases the signal-to-noise ratio (SNR) achieved with MR. When exposed to the magnetic field, the magnetic dipole vectors of MR-active nuclei (such as ${ }^{13} \mathrm{C}$ ) are aligned either parallel or antiparallel with the external field, and there is usually only a small excess of parallel spins (the polarization percentage). However, higher polarization values can be reached for short periods of time via hyperpolarization, producing larger vectors and facilitating high-SNR data and shorter acquisition times in MRS imaging acquisitions [110].

\section{Interpretation guidelines}

In clinical practice, tumor spectroscopic phenotype can be evaluated in three ways: (a) qualitative evaluation is performed by merely checking absence, presence, or change of certain metabolites; (b) semiquantitative evaluation is based on two different approaches: the calculation of metabolite ratios (e.g., $\mathrm{Cho}+\mathrm{Cr} / \mathrm{Ci}$ ratio, which correlates significantly with the probability of malignancy in prostate) or the evaluation of the area under the metabolite peaks of interest; and (c) finally, absolute quantification of the concentration of a metabolite with the use of a reference standard for calibration.

\section{Clinical value}

Spectroscopy of cancer can characterize critical tumor metabolic pathways (including membrane turnover, lipids, and energy metabolism) and can depict specific tissue markers, such as $\mathrm{N}$-acetyl-aspartate (NAA) (a specific neuronal marker) or Ci. MRS technique in tumors is mainly based on detecting the elevation of certain metabolites (such as Cho) or the absence or decrease of normal metabolites (e.g., $\mathrm{Ci}$ in the prostate) [108, 109-112]. However, its technical complexity, long 
Table 3 Main metabolites studied in ${ }^{1} \mathrm{H}$-MRS and their biological significances

\begin{tabular}{|c|c|c|}
\hline Metabolite & Biological meaning & ppm \\
\hline $\begin{array}{l}\text { Cho } \\
\text { (total Cho-containing } \\
\text { compounds) }\end{array}$ & $\begin{array}{l}\text { A metabolic marker cell membrane } \\
\text { synthesis and repair. } \\
\text { Related to cell density and } \\
\text { membrane integrity }\end{array}$ & 3.22 \\
\hline $\begin{array}{l}\mathrm{Cr} \\
\text { (from both creatine } \\
\text { and phosphocreatine, } \\
\text { often called referred to } \\
\text { as total creatine peak) }\end{array}$ & Reflects "cellular energetics" & 3.02 \\
\hline Lac & $\begin{array}{l}\text { Glycolysis } \\
\text { Usually lactate is present only in } \\
\text { minimun amounts (i.e., in the brain) } \\
\text { and is not depicted using the } \\
\text { normal spectroscopic techniques. }\end{array}$ & $\begin{array}{l}\text { Doublet } \\
\text { peak at } \\
1.33 \\
\text { ppm }\end{array}$ \\
\hline Lip & $\begin{array}{l}\text { May indicated tumor necrosis or } \\
\text { voxel contamination by diploic } \\
\text { space fat, scalp and subcutaneous } \\
\text { tissue }\end{array}$ & $\begin{array}{l}0.9 \text { and } \\
1.3 p p m\end{array}$ \\
\hline
\end{tabular}

Specific metabolites in brain H-MRS

NAA

$\mathrm{ml}$

Specific metabolites in Prostate H-MRS

$\mathrm{Ci}$
A marker of neuronal and axonal density and viability

The exact role of NAA in human brain metabolism is uncertain. It is postulated to be involved in lipogenesis pathways Largest peak in a "normal" H- MRS brain spectrum.

A glial marker located in astrocytes 3.56

Involved in osmoregulation and

volume regulation

Normal human prostate gland accumulates and secretes extraordinarily high Ci levels
Absence of neurons and axons in most tumors but also in white matter diseases (i.e., multiple sclerosis)

Increased values
Due to cell proliferation and to
breakdown of cell membranes.
Higher Cho levels are shown in
higher grade tumors compared
with lower-grade tumors

Decreased phospocreatine (PCr) is an inconstant finding in tumors. Represents a low- energy status of glycolisis in primary tumors (high grade gliomas) and in metastatic tumors is the effect of the lack of $\mathrm{PCr}$ in most tissues.

Increased Lac is the effect of the high rate of glycolisis. Lac is an end product of glycolysis and increases rapidly during hypoxia It accumulates in necrotic or cystic areas

The rise of Lip is detected in various cellular processes such as necrosis, growth arrest, inflammation, malignancy and apoptosis.
It is a relative marker for lowgrade gliomas. Reduced in highgrade tumors
In prostate cancer

Ci levels fall due to consumption of $\mathrm{Ci}$ to supply energy to proliferating cells)

Ala alanine, Cho choline, $\mathrm{Ci}$ citrate, $\mathrm{Cr}$ creatine, Lac lactate, Lip lipids, $\mathrm{ml}$ myo-inositol, NAA N-acetylaspartate, ppm parts per million

measurement times required, and frequent low-quality spectra have limited its widespread use.

\section{- Hydrogen MRS}

Characterization of intracranial tumors is a challenge for imaging. In this setting, main ${ }^{1} \mathrm{H}$-MRS studies have focused on the assessment of intracranial tumors [113]. Spectroscopy offers additional information related to tumor proliferation and metabolic changes or neuronal damage, which can be used to establish noninvasively the diagnosis and grading of brain tumors. An increased Cho peak along with decreased NAA is an important diagnostic feature in brain tumors. Besides, increased Lip seems to be secondary to necrosis and membrane breakdown. Cancer cells also rapidly metabolize glucose to form Lac and its levels appear to correlate with grade and type of tumor in the brain. Finally, a myo-inositol (MI) peak is typically present in glial tumors at $3.5 \mathrm{ppm}$ chemical shift. ${ }^{1}$ H-MRS has shown clear advantages for the assessment of central nervous system neoplasms including differentiating between tumors from other lesions, characterizing types and grades of tumors, offering prognostic data, planning therapy with delineation of tumor involvement and definition of the target volume for radiation therapy, monitoring tumor response, and detecting tumor relapse.

Technical advances allowed the use of MRS in other organs, mainly prostate and breast [108]. PCa is characterized by combinations of elevated Cho and reduced $\mathrm{Ci}$. ${ }^{1} \mathrm{H}$-MRSI in prostate can improve tumor detection, 

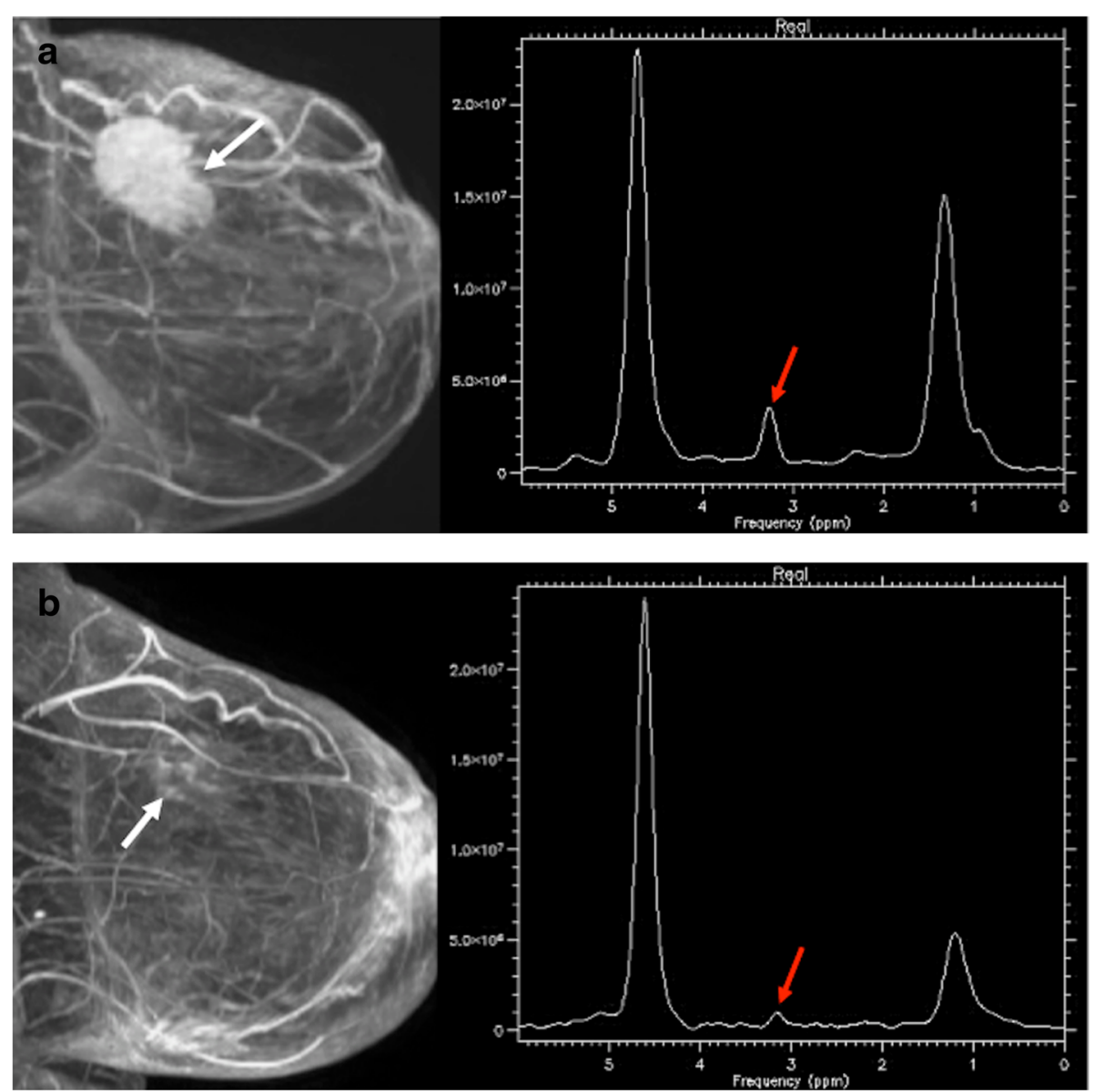

Fig. 16 A 56-year-old woman with an invasive ductal carcinoma of the breast. Pretherapy (a) the sagittal reformatted maximum intensity projection (MIP) image from DCE-MRI (left) demonstrating a 5-cm enhancing mass (white arrow). MR spectrum (right) depicts a marked choline peak (red arrow). Images obtained after chemotherapy and anti-HER2 therapy with trastuzumab (b) evidenced a residual lesion. Sagittal reformatted maximum intensity projection (MIP) image from DCE-MRI demonstrated discrete dots of enhancement (white arrow), while MR spectrum showed a decreased choline peak (red arrow). Tumorectomy revealed residual fibrosis without tumor cells

localization, and staging; assessment of tumor aggressiveness; and evaluation of tumor response. A metaanalysis of the literature to assess the accuracy of MRS in diagnosing $\mathrm{PCa}$ evidenced that the pooled weighted sensitivity and specificity varied depending on the $(\mathrm{Cho}+\mathrm{Cr}) / \mathrm{Ci}$ ratios used, ranged between $64-82$ and $68-86 \%$, respectively. Moreover, a positive correlation was found between these ratios and the pathologic Gleason score with a large proportion of nonsignificant tumors (Gleason score $\leq 6$ ) that do not present abnormal metabolite ratios [114]. However, at present, the clinical use of MRS in prostate has been reduced due to its technical complexity. Thus, version 2 of the Prostate Imaging-Reporting and Data System (PI-RADS v2) does not include the use of MRS.

In breast tumors, an increased Cho peak has been described in malignant breast lesions (Fig. 16). A meta- analysis of the diagnostic performance of single-voxel ${ }^{1} \mathrm{H}-\mathrm{MRS}$ of the breast reported a pooled sensitivity ranged between 71 and $74 \%$, and a pooled specificity between 78 and $88 \%$. However, in the case of non-mass lesions or small masses (between 5 and $10 \mathrm{~mm}$ in diameter) or foci $(<5 \mathrm{~mm}$ in diameter $)$, spectroscopy was scarcely useful [115].

\section{- Phosphorus MRS}

Malignant transformation has been found to alter the profile of the Cho compounds (related to membrane turnover) and the signals from energy metabolites such as nucleoside phosphates and phosphocreatine. Although ${ }^{31} \mathrm{P}$ MRS may monitor these metabolic changes, its clinical use has been limited due to technical complexity and low sensitivity of MR systems [111, 112]. 


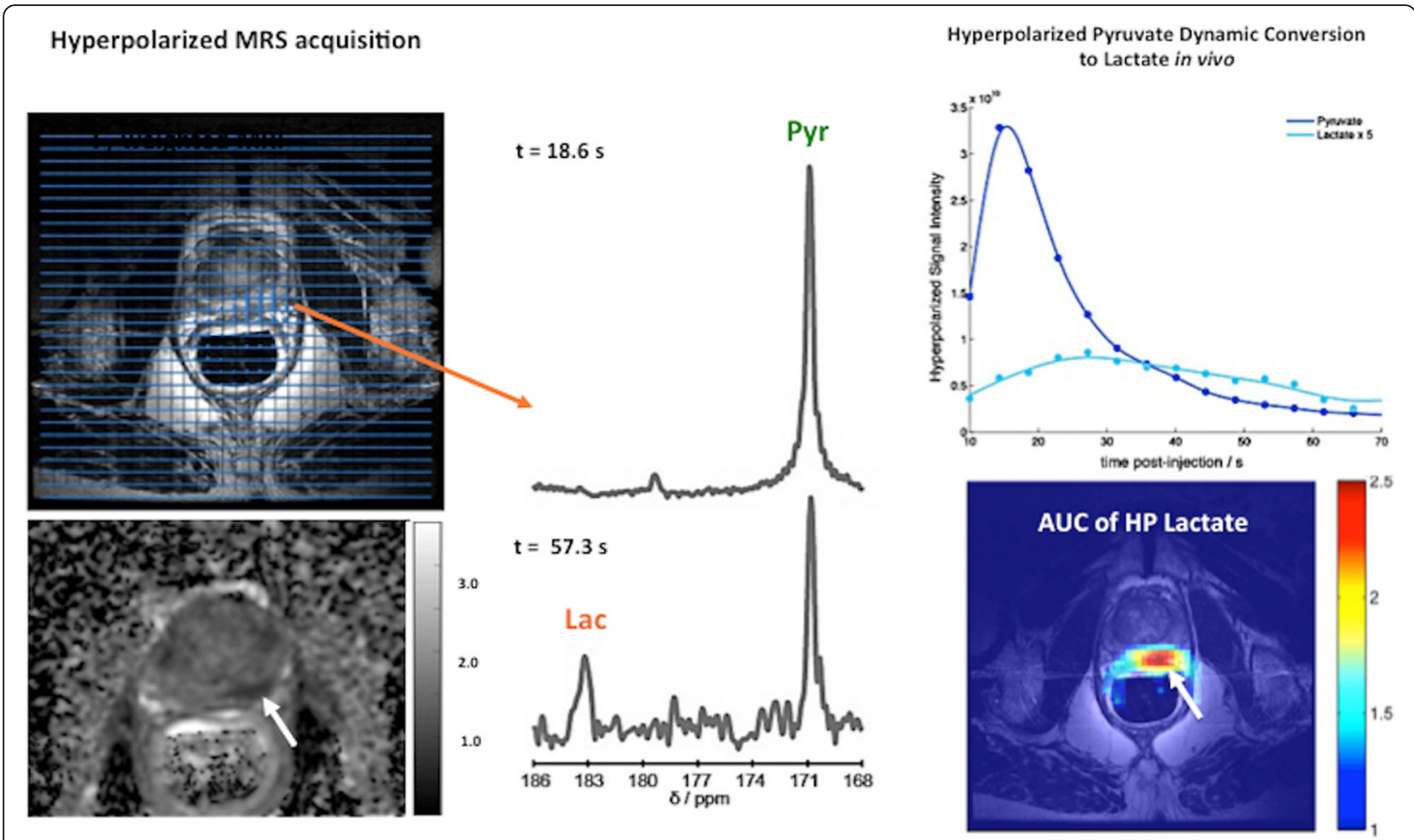

Fig. 17 A 71-year-old man with a Gleason 7 prostate cancer (PSA 6.05). A suspicious area with low ADC values was depicted in the left peripheral area (white arrow). The hyperpolarized ${ }^{13} \mathrm{C}$ spectra and the time course for the dynamic conversion hyperpolarized [1-13C] pyruvate to lactate following the injection of hyperpolarized pyruvate were revaluated (top, right). Note the change of the MR spectra with the pyruvate quickly reached a maximum at $t: 57.3 \mathrm{~s}$ (bottom, middle) before being converted to lactate. Compared with the spectrum at $t: 18.6 \mathrm{~s}$ (top, middle). [Images courtesy of Kayvan R Keshari, PhD. Laboratory Head. Memorial Sloan Kettering Cancer Center]

\section{- Hyperpolarized MRSI}

Currently, there is a limited clinical use of ${ }^{13} \mathrm{C}$ hyperpolarization in clinical studies and the majority is focusing on the pyruvate metabolism in PCa (Fig. 17). Hyperpolarized $\left[1-{ }^{13} \mathrm{C}\right]$-pyruvate has demonstrated increased lactate labeling in tumors and decreasing metabolism to bicarbonate [116].

\section{Imaging tumor proliferation}

Sustained proliferation is a fundamental part of cancer development and progression. The imaging of tumor proliferation may provide valuable information for tumor diagnosis and characterization and early assessment of the response to therapy.

\section{Biological bases of tumor proliferation}

EGFR is commonly upregulated in cancers. EGFR over-activates downstream pro-oncogenic signaling pathways, including the Ras-Raf-mitogen-activated protein kinase (MAPK) pathway and the PI3 kinase (PI3K)-Aktmechanistic target of rapamycin (mTOR) pathway. These pathways activate cell growth, proliferation, and survival.

\section{Imaging approaches to tumor proliferation}

Noninvasive imaging-based assessment of cellular proliferation in cancer is mainly based on radiotracers that track the thymidine salvage pathway of DNA synthesis.

\section{- PET imaging of tumor proliferation}

$\left[{ }^{18} \mathrm{~F}\right]$-3-fluoro-3-deoxythymidine (FLT) is a nucleosideanalog imaging agent that presents intracellular accumulation of the tracer during the S-phase of the cell cycle through the action of the thymidine kinase-1 (TK1). Since this kinase is primarily expressed in dividing cells, FLT uptake is essentially limited to proliferating cells. FLT uptake has been shown to correlate with Ki-67 expression, a classic marker of tumor proliferation [117]. FLT has been rarely used for tumor response evaluation due to the limited knowledge of the factors determining FLT uptake and therapy-induced changes of its retention. Nevertheless, published data suggest that decreased radiotracer uptake generally reflects the effects of anticancer therapies, although it should be taken into account that drugs impacting TK1 (such as antifolates) may induce a flare effect. 
Other radiotracers (Cho-PET) and different imaging techniques (MRSI or DWI) may also offer an indirect assessment of tumor proliferation. Cho metabolism is involved in the synthesis of Lip required for cell membrane turnover in tumor proliferation. In this setting, MRSI Cho peak and Cho-PET uptake may indirectly evaluate the cell proliferation. Thus, a number of studies have found significant correlations between the SUV of Cho-PET or Cho peaks on MRSI and Ki-67 proliferation scores. Changes in Cho metabolism are being used in oncology for diagnosis, prognosis, and monitoring response. However, it is also necessary to consider that Cho is not a specific cancer tracer (e.g., normal testicles show elevated Cho peaks and granulomatous LNs may present increased uptake on Cho-PET).

DWI may also reflect other histopathological features, such as proliferation potential. However, based on a recent meta-analysis, the correlation of DWI-derived parameters and tumor proliferation based on the expression of cell proliferation markers (e.g., Ki67) showed a great variability depending on tumor type $[118,119]$.

\section{Evaluation of tumor vasculature-angiogenesis}

Tumor angiogenesis is the process of developing new blood vessels in order to supply oxygen and nutrients to support the growth of tumors. Angiogenesis is a key cancer hallmark required for invasive tumor growth and metastasis development and constitutes a basic target in the therapy of cancer. Imaging modalities used to evaluate tumor neovasculature mainly include CT, MRI, or US [120-125]. All of them have strengths and weaknesses regarding availability, sensitivity, accuracy, biological significance of the obtained data, technical reproducibility, methods for image quantification, provided parameters, and the anatomical areas that can be imaged.

\section{Biological bases of angiogenesis}

Most solid tumors arise as avascular cellular masses that exclusively depend upon oxygen delivery by diffusion. When tumor size exceeds oxygen diffusion distances, regions of hypoxia will develop within the mass. This feature causes the secretion of angiogenic factors (particularly the vascular endothelial growth factor, VEGF), which activate the angiogenic switch. However, tumor vasculature is highly abnormal. Tumor vessels are often larger but less numerous and more ineffective than those of normal tissues. Besides, tumor blood vessels are heterogeneous and abnormal with regard to organization, function, and structure. The combination of these vascular characteristics causes that the overall BF tended to be significantly lower in tumors and the subsequent development of hypoxia. Unfortunately, imaging techniques used in clinical practice usually check the effects of angiogenesis on tumor vasculature, not the angiogenic process itself [120-126].

\section{Technical features}

Imaging plays a central role in the clinical evaluation of angiogenesis. Anatomical imaging remains the mainstay for tumor evaluation pinpointing sites of enhancement and evaluating the degree of enhancement. New technologies, such as dual-energy CT, may have an added value over conventional $\mathrm{CT}$ imaging for tumor assessment. In this setting, quantitative iodine concentration maps obtained with spectral CT have shown good correlations with conventional $\mathrm{CT}$ perfusion measurements in different tumor types [127]. Imaging techniques can also characterize functional abnormalities of vessels and can assess vascular heterogeneity. Different imaging techniques with and without the use of exogenous contrast media have been used for the functional evaluation of tumor vasculature. DCE techniques including CTP, DCE-US, DCE-MRI, or DSC-MRI are the most common imaging methods for assessing tumor vasculature [120126]. These imaging techniques acquire a series of images through a region of interest before, during, and after the intravenous injection of a contrast agent. DCE techniques may provide information related to tumor vessels function (perfusion or permeability). Data obtained depend on multiple features including imaging technique, the type of contrast agent, and the method of analysis. On its part, IVIM and ASL constitute the main non-contrast-enhanced imaging techniques for the evaluation of tumor vasculature. CTP evaluates temporal changes in tissue attenuation following the intravenous administration of contrast media. In this context, iodine concentration changes may represent an indirect reflection of tissue vascularity and vascular physiology [126] (Fig. 18). On its part, DCE-US with gas-filled microbubbles offers potential for the evaluation of tumor perfusion. Microbubbles flood across tumor capillary bed and the gas they contain contracts and expands under the alternating higher and lower pressure phases of the US beam, producing harmonics that can be detected for extracting kinetic characteristics from DCE-US echo intensity (which is directly related to local vascularization and contrast-agent concentration) versus time data [128]. DCE-MRI calculates tissue perfusion parameters by evaluating $\mathrm{T} 1$ shortening induced by a gadolinium-based contrast agent bolus as it distributes in the tumor vasculature and leaks across permeable vessels. The resulting signal intensity-time curve reflects a composite of tissue perfusion, vessel permeability, and extravascular-extracellular space and can be analyzed to derive a number of potential biomarkers of the vascular microenvironment. DSC-MRI or T2*-weighted DCE is based on the local magnetic inhomogeneities that arise on 


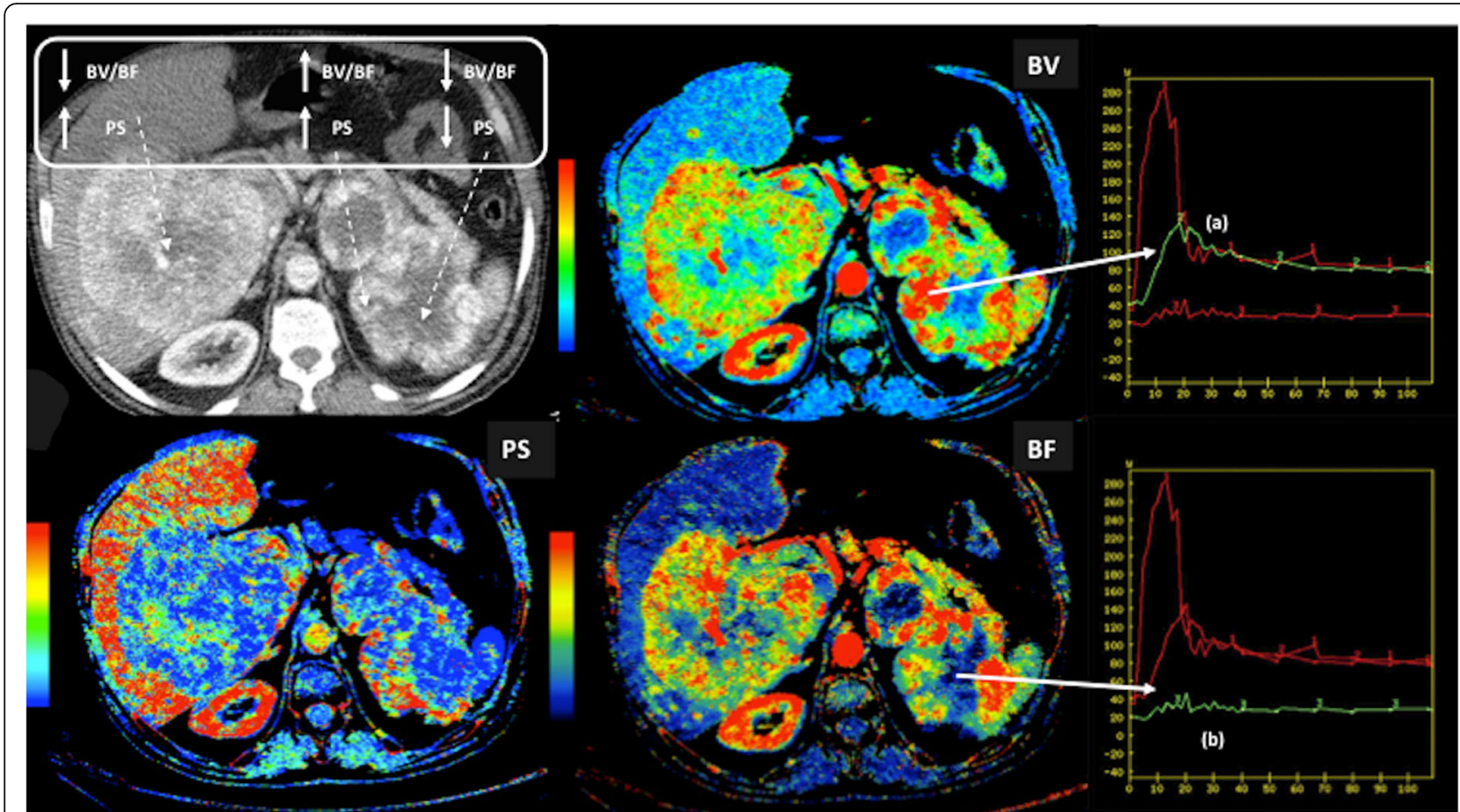

Fig. 18 Perfusion CT exam in a 42-year-old man with a metastatic renal carcinoma. Blood flow (BF), blood volume (BV), and permeability (PS) parametric maps evidenced the heterogeneity of the functional status of the vasculature within the tumor with several combinations of the obtained parameters (top-left) and clear differences between the time density curves coresponding to the peripheral areas of viable tumor with increased BV, BF, and PS (a) with a wash-in/wash-out pattern and the central necrotic necrotic areas (a)

the boundaries between structures that differ in their magnetic susceptibility, leading to signal reduction on $\mathrm{T} 2$ or T2*-weighted gradient-echo sequences. The transient signal loss induced by the pass of the contrast agent across tissue vascular network is proportional to the local BV and BF. DSC studies are basically limited to the evaluation of brain tumors. Finally, ASL is based on the principle of magnetically labeling inflowing arterial blood protons inverting the bulk magnetization of the blood water protons prior to their entry into the tissue of interest. A control image, in which the blood water magnetization is not inverted, is also acquired. The signal difference between labeled and control images will be proportional to BF. Quantification allows for regional and global assessments of perfusion. ASL is being applied in brain imaging (Fig. 19) [129].

\section{Interpretation guidelines}

Many features need be considered in the acquisition and analysis of DCE exams, including the organ studied and the clinical setting. The characteristics of perfusion data acquisition (temporal resolution, length, etc.) and the model of analysis of enhancement kinetics directly influence the calculation of vascular parameters. Analysis and interpretation of DCE-imaging data can be performed with different approaches [120, 121]:

- Qualitative analysis: Visual assessment of pre- and postcontrast images, or of the shape of the timeintensity curves (TIC) represents the most simple way of analysis. Curve characteristics, including the speed of the filling phase, the maximum peak intensity, and the morphology following the peak of enhancement (persistent increase, plateau, or washout), are evaluated. This approach has shown clinical utility for the characterization of breast, soft-tissue, and prostate tumors, although does not produce a quantifiable index.

- Semiquantitative analysis: This type of evaluation is based on performing a direct analysis of changes in SI using semiquantitative indices. Main descriptors that characterize the shape and structure of the curves include time to peak enhancement, initial area under the curve (IAUC), maximum enhancement, etc. These parameters have been used in the clinical evaluation of brain, breast, and prostate tumors. Unfortunately, they do not present a clear defined relationship with tumor physiology.

- Quantitative analysis: The combination of DCE imaging with mathematical modeling of the contrast 

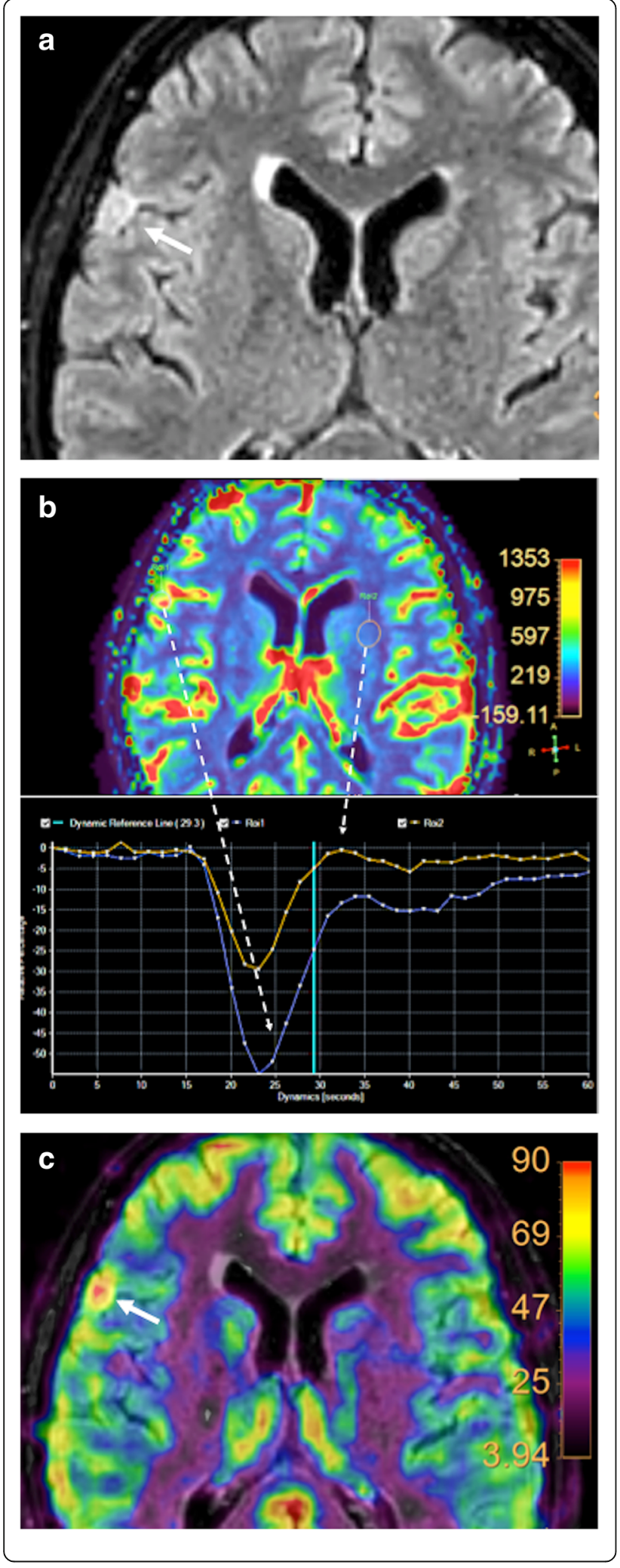

Fig. 19 Brain perfusion in a 55-year-old woman with a meningioma. a An axial fluid attenuation inversion recovery (FLAIR) image of the brain demonstrated a hyperintense extra-axial insular lesion (white arrow). Both (b) dynamic susceptibility contrast (DSC)-MRI and (c) arterial spin labelling (ASL) parametric maps demonstrated and increased perfusion in the mass. Comparison to normal brain parenchyma evdenced a higher decrease in MR signal intensity curves during the first-pass of the contrast bolus (b, blue curve)

agent kinetics enables quantitative assessment of the structural and functional changes in tumor microvasculature. Measured TICs must be converted into concentration of contrast-time curves and modeled in a pixel-wise fashion to create functional maps of vascular parameters. In general, the complexity of the quantitative analysis and the lack of consensus have limited its applications to clinical trials in academic centers.

\section{Clinical value}

The angiogenic phenotype shows a great heterogeneity among different type of tumors and even in the same tumor type or in different regions of the same tumor. Imaging-based phenotypes are important features for the decision-making process in oncology, including tumor diagnosis, characterization and grading, biopsy guiding, staging, prognostic biomarker and response prediction, therapy planning, assessment of treatment response, detection of relapsing tumor, and development of new cancer drugs. Tumor vasculature provides an attractive target for anticancer therapies [120, 121, 126]. DCE-imaging is now frequently used in early clinical trial assessment of angiogenic inhibitors [43, 126, 130]. In these patients, therapy response is associated to a significant decrease in perfusion and permeability-related parameters. Moreover, an early reduction in vascular parameters following therapy is usually associated to an improved patient's outcome.

\section{Imaging cell death in cancer}

Imaging programmed cell death would be useful both in clinical care and in drug development.

\section{Biological bases of cell death}

Cell death has been classified, on the basis of morphologic criteria, as programmed cell death (apoptosis) or non-regulated (necrosis) [131]. Necrosis is characterized by loss of plasma membrane integrity, which frequently causes marked inflammation, tissue destruction, and fibrosis. On its part, apoptosis is accompanied by a series of complex morphological changes, including cell shrinkage, chromatin condensation, and formation of apoptotic bodies. Apoptotic bodies are subsequently ingested by adjacent cells and 
phagocytes without provocation of an inflammatory response. Apoptosis is also characterized by several molecular alterations, including the externalization of phosphatidylserine to the outer leaflet of the plasma membrane bilayer and the activation of caspases [132]. Phosphatidylserine exposure by dying cells has been evaluated with radiolabeled annexin V. However, it has not become routine in clinical practice.

\section{Technical features}

Radiotracers and modalities for the imaging of apoptosis include phosphatidylserine-binding agents (annexin V) and MR-based imaging with the assessment of mobile lipids and Cho with ${ }^{1}$ H-MRS and DWI [131-134] (Figs. 6 and 7).

\section{Clinical value}

There is a limited use of clinical imaging in the evaluation of cell death, although MRI seems to be a promising tool. Apoptosis and necrosis exhibited different changes on MR exams including T1- and T2-weighted sequences, DWI, and MRS [133, 134]. Necrosis secondary to therapy is accompanied by an early increase in ADC values, while apoptotic treatments do not cause significant ADC changes [133]. In the case of ${ }^{1} \mathrm{H}$-MRS, this technique demonstrates apoptosis- and necrosis-specific changes on cell mobile Lip peaks [132].

\section{Imaging of cancer heterogeneity}

Tumors are biologically heterogeneous at the morphologic, histological, and genetic levels. Imaging has begun

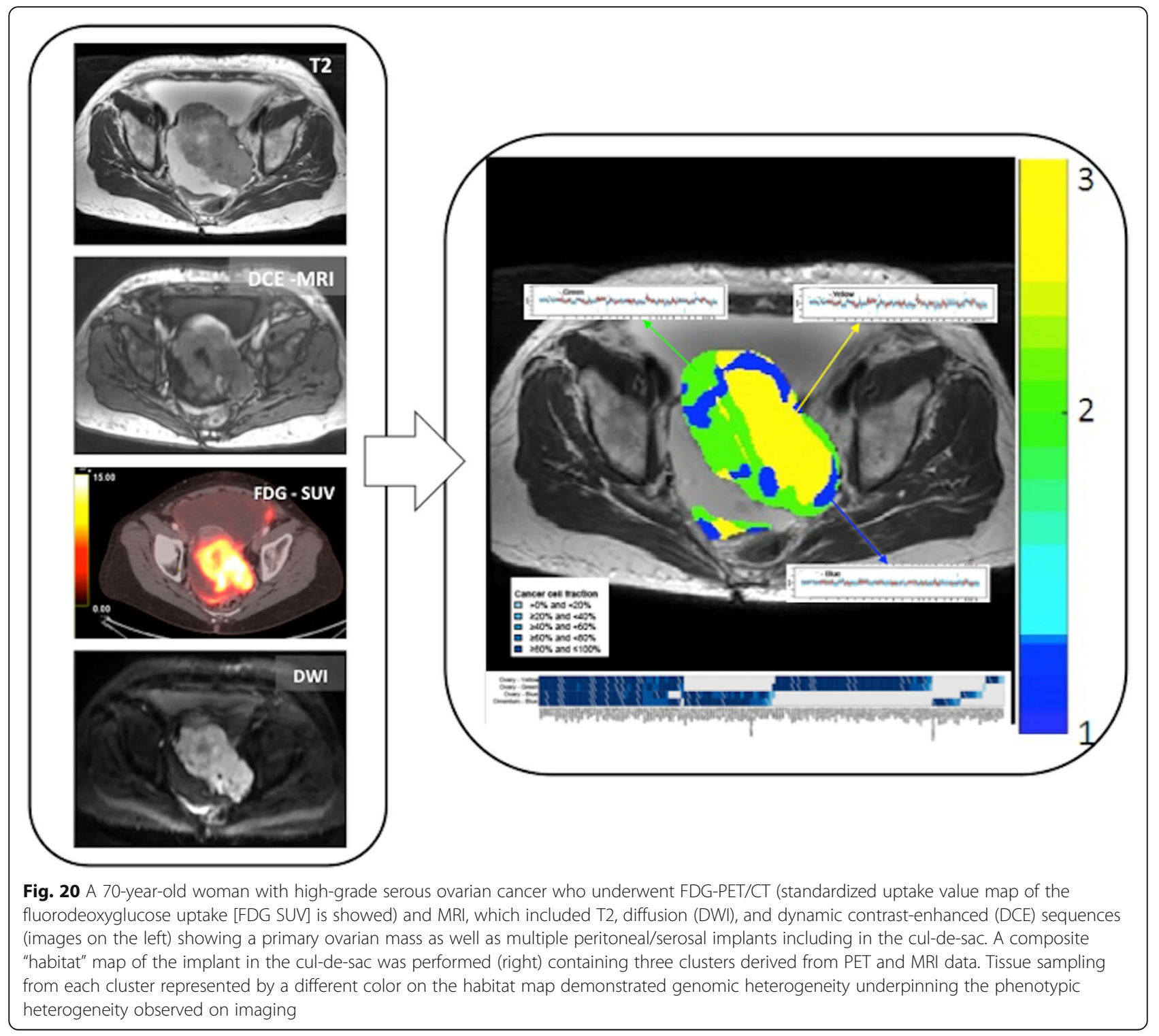




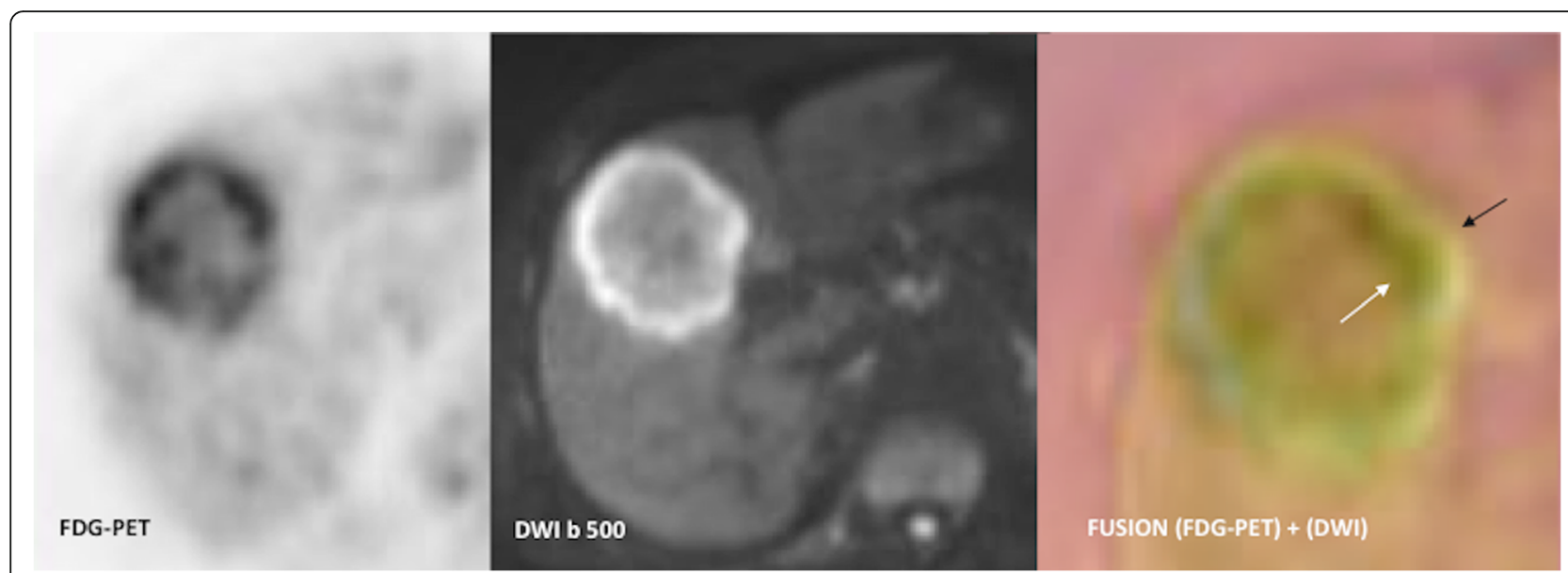

Fig. 21 Colorectal cancer liver metastasis in a 56-year-old man. FDG-PET (left) and b500 diffusion-weighted (middle) images demonstrated the presence of a mismatch between the obtained parameters. Note that the size of the FDG abnormality is smaller than the diffusion one (black arrow) (right). Tumor biology may explain this feature. Higher FDG uptake occurs at the edge of the necrotic cavity (white arrow) which is of relative low SI on b500 image. The edge of the necrotic cavity usually represents an area of relative tumor hypoxia, which may promote a high metabolic activity (vascular metabolic-mismatch). On its part, the periphery of the mass generally presents good perfusion and it is the most cellular area of the tumor, explaining the restricted diffusion at this level
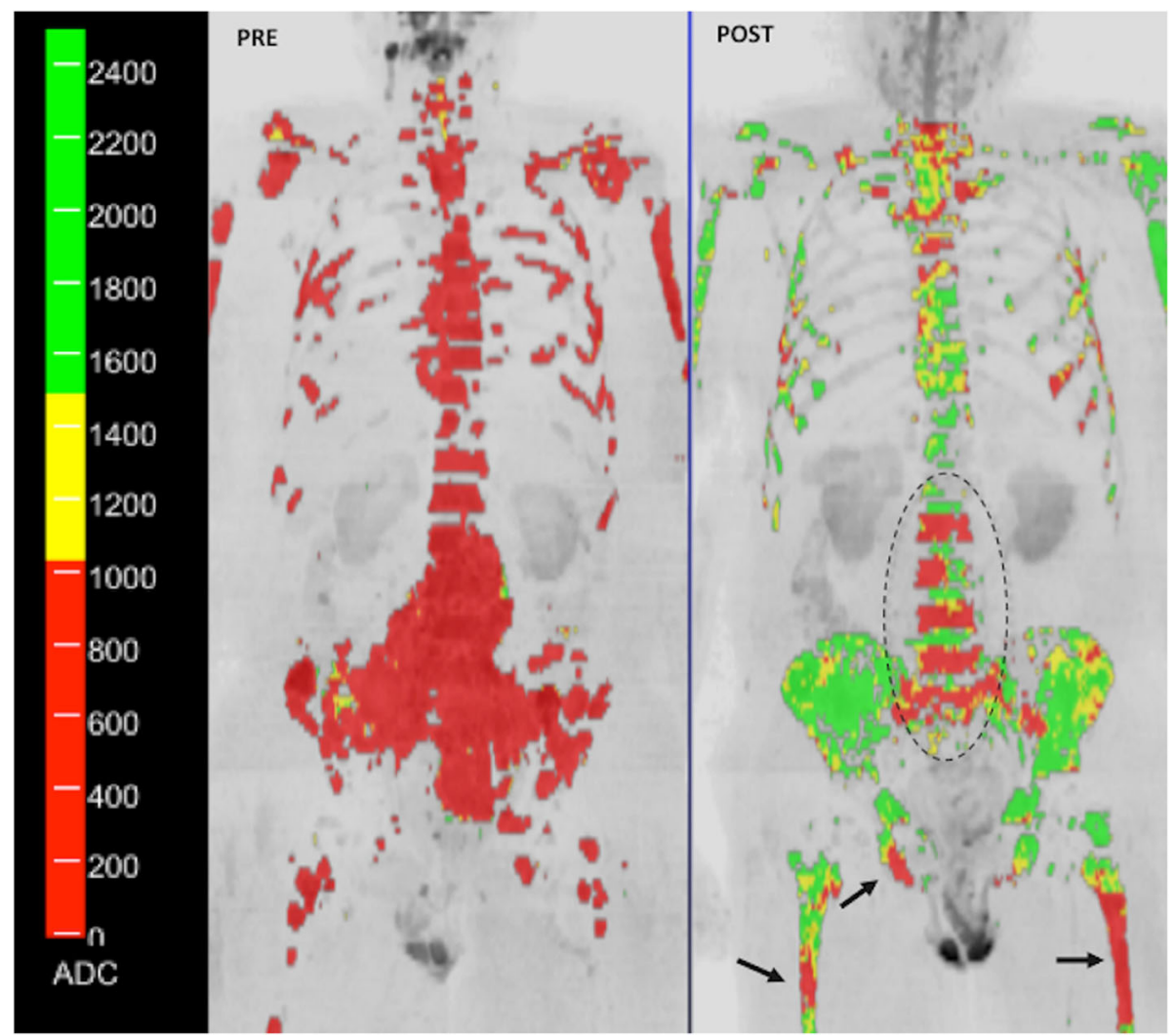

Fig. 22 Whole-body DWI evaluation in a 72-year-old man with metastatic prostate cancer treated with (docetaxel + prednisone). A comparison between images pre (left) and posttherapy (right) demonstrated that tumor volume decreased $\left(1280 \mathrm{~cm}^{3} \rightarrow 640 \mathrm{~cm}^{3}\right)$ and mean ADC moved from 0.7 to 1.61 confirmed an increasing \% of voxels at higher ADC values after therapy consistent with reductions in cellularity due to tumor necrosis. However, tumor response was heterogeneous in this patient and there were some anatomical areas that presented a limited tumor response (black dotted circle on lumbar spine and black arrows) 
to map and track the presence of phenotypic heterogeneity between (intertumor) and within tumors (intratumor) of a given patient.

\section{Biological bases}

Genetic variation is undoubtedly the most established foundation of both intra- and intertumor heterogeneity. However, other features such as epigenetics or tumor microenvironment also play a role on heterogeneity [135]. Intertumoral heterogeneity has resulted in the classification of tumor subtypes, which are characterized by distinct morphology, functional, molecular and genetic profiles, and expression of specific markers. On its part, intratumoral heterogeneity manifests as variations within the tumors (Fig. 20). Distinct tumor genotypes and/or phenotypes usually associate divergent biological behaviors, and this circumstance may have prognostic significance and may influence response to therapy. In general, the degree of intratumor heterogeneity tends to increase as tumors grow and greater heterogeneity tends to be associated to a relatively poor clinical outcome and resistance to therapy.

\section{Technical features}

Tumor spatial and temporal heterogeneity is a critical oncologic feature that can be reflected in medical images and interpreted based on different approaches: (1) evaluating simple qualitative descriptors (e.g., tumor margin or shape); (2) quantifying parameter distributions with histogram-based analysis (discarding spatial relationship between voxels and treating data as a list of continuous variables); (3) quantifying spatial complexity (e.g., texture, fractal, or cluster analysis); (4) grouping voxels with common biological features (parcellation); or (5) analysis assessing quantitatively the spatial distribution of parameters (e.g., parametric maps) (which tend to derive average parameter values), etc. [3, 135-139].

\section{Clinical value}

The advantage of diagnostic imaging techniques in the assessment of tumor heterogeneity is their noninvasive nature and the fact that the whole tumor may be evaluated, whereas histological techniques are invasive and limited to a discrete set of tumor samples. There is a growing evidence that qualitative or quantitative evaluation of heterogeneity presents clinical advantages for screening, diagnosis, grading, staging, and assessment of response therapy in tumors [138]. Unfortunately, many parameters, such as kurtosis, have no clear biological correlate making biological validation difficult. Moreover, in order to improve a global assessment of tumor heterogeneity, whole-body imaging techniques (e.g., PET or WB-DWI) offer an ideal solution as they allow a global assessment of tumor burden.

\section{Future trends of imaging in cancer}

There are extraordinary future opportunities for imaging techniques in tumor biology evaluation, including the development of imaging biomarkers and radiomics/ radiogenomics, the use of multiparametric analysis and artificial intelligence, and theranostic. To date, most research has been focusing on validating biomarkers extracted from tissue or blood samples, which has improved patient stratification and assisted oncologic drug development. Imaging techniques can evolve into clinically useful biomarkers for tumor assessment and evaluation of therapy response. The advantages of imaging are its versatility, its widespread disponibility, its capability of evaluating whole tumor burden, and its relatively noninvasive nature [140-144]. Adequate quantification of imaging biomarkers is of paramount importance when extracted data are going to be used in patient management. In this setting, data must be reproducible and the technology used to extract them must be standardized. Biomarkers precise a complex process of validation and qualification [140, 143]. On the other side, in recent years, imaging has been boosted by the technological development generating a large volume of data. Such information has increased in complexity and may offer prognostic value and may reveal meaningful information for decision-support in cancer diagnosis and treatment. Radiomics refers to the extraction and quantitative analysis of tumor characteristics from medical images. On its part, radiogenomics investigates the relationship between imaging features and gene expression. The -omic approach is based on numerical calculus and computer science methods, allowing the management and analysis of a very large number of variables for each sample and modality. There is a rapid increase in the number of publications that have highlighted the utility of imaging -omics in many different tumor types and based on different imaging techniques [145-155]. Radiomics and radiogenomics approaches may show clinical utility for assisting in cancer diagnosis, assessment of tumor aggressiveness, response assessment, and evaluation of patients' outcome. Integrating (quantitative) imaging data with other relevant information (clinical, pathological, etc.) and multi-omics (genomics, proteomics, and metabolomics) will be essential for unraveling tumor heterogeneity and making real-time clinical decisions for patients in personalized medicine. However, this process still necessitates improvement and standardization in order to achieve routine clinical adoption. In this scenario, computers may be useful tools for the assessment of tumor characteristics and for the evaluation of therapy response. Computers can learn (machine learning) to extract meaningful patterns (including patterns that are beyond human perception) by processing massive datasets (big data) through 
mathematical models (algorithms). Machines can also correct algorithm mistakes by training. Machine learning algorithms are just useful components of computer-aided diagnosis and decision support system in oncology. Imaging representation and interpretation of tumor biology will require computational models to understand and predict the complex nonlinear dynamics that result in combinations of imaging features [156-158]. 3D printing is also an emerging computer-based technique that may be useful in oncology for research, surgical planning (using an exact 3D model of the patient's organs to practice a procedure), device designing and manufacturing, and tissue or organ replacement [159]. The analysis of multi-dimensional imaging datasets is also increasingly required for imaging tumor phenotype. The correlation between imaging features obtained with different techniques must be explored for understanding the underlying tumor biology (Fig. 21). Significant differences in vascular, physiological, and metabolic characteristics have been identified in metastatic and nonmetastatic cancers. In this setting, high glycolytic activity and poor perfusion (vascular-metabolic mismatch) result in an aggressive tumor phenotype [160]. Finally, advances in the understanding of cancer biology together with developments in diagnostic technologies, and expansion of therapeutic options have all contributed to the concept of personalized cancer care with accurate and specific targeting of cancer cells. Theranostics is the systematic integration of targeted diagnostics and therapeutics. Imaging may select the therapeutic choice and may monitor subsequent changes in the biological characteristics of the tumor $[161,162]$.

In conclusion, clinical imaging has tremendous potential in the evaluation of a wide spectrum of biological tumor characteristics at all stages of a cancer patient's management and in drug discovery. Imaging techniques have also the ability to show the spatial and temporal heterogeneity of tumors (Fig. 22). In the time of precision oncology, clinical imaging represents a basic decision-making tool in cancer patients.

\section{Additional file}

Additional file 1: Table S1. Imaging Techniques in Tumor Evaluation. (DOCX $36 \mathrm{~kb}$ )

\footnotetext{
Abbreviations

ADC: Apparent diffusion coefficient; APT: Amide proton transfer; ASL: Arterial spin labeling; BF: Blood flow; BM: Bone marrow; BOLD: Blood oxygenation level dependent; BV: Blood volume; CBF: Cerebral blood flow; CBV: Cerebral blood volume; CEST: Chemical exchange saturation transfer; Cho: Choline; Ci: Citrate; Cr: Creatine; CT: Computed tomography; CuATSM: Diacetylbis(N4-methylthiosemi-carbazone) copper(II)); CXCR4: C-X-C motif chemokine receptor 4; D: Tissue diffusivity; D*: Perfusion-related diffusion coefficient; Dapp: Non-Gaussian diffusion coefficient; DCE: Dynamic contrast-enhanced; DKI: Diffusion kurtosis imaging; DSC-MRI: Dynamic susceptibility contrast-enhanced MRI; DTI: Diffusion tensor imaging; DWI: Diffusion-weighted imaging; ECM: Extracellular matrix;
}

EGFR: Epidermal growth factor receptor; EUS: Endoscopic ultrasound; f: Perfusion fraction; FAZA: Fluoroazomycin arabinoside; fD*: Relative perfusion; FDG: Fluorodeoxyglucose; FID: Free induction decay; FLT: Fluorothymidine; FMI: Functional-molecular imaging; FMISO: Fluoromisonidazole; Glut: Glucose transporters; H\&N: Head and neck; IAUGC: Initial area under gadolinium curve; IVIM: Intravoxel incoherent motion; Kapp: Apparent kurtosis; kep: Rate constant;

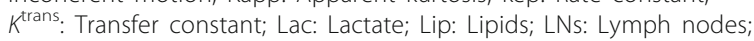
MAMMI-PET: Mammography with molecular Imaging PET;

MAPK: Mitogen-activated protein kinase; MI: Myo-inositol; MRE: Magnetic resonance elastography; MRI: Magnetic resonance imaging; MRS: Magnetic resonance spectroscopy; MRSI: Magnetic resonance spectroscopic imaging; MT: Magnetization transfer; mechanistic target of rapamycin; MTT: Mean transit time; MVD: Microvessel density; NAA: N-acetyl-aspartate; NETs: Neuroendocrine tumors; PCa: Prostate cancer; PET: Positron emission tomography; PI3k: PI3 kinase; PI-RADS v2: Prostate imaging-reporting and data system version 2; ppm: Parts per million; PSMA: Prostate-specific membrane antigen; R2*: Transverse relaxation rate; RCC: Renal cell carcinoma; ROI: Region of interest; SEM: Stretched-exponential model; SI: Signal intensity; SNR: Signal-tonoise ratio; SPECT: Single-photon emission computed tomography; SSTR: Somatostatin receptors; SUV: Standardized uptake value; TIC: Timeintensity curve; TK1: Thymidine kinase-1; TME: Tumor microenvironment; TOLD: Tissue oxygen level dependent; US: Ultrasound; ve: Leakage space fraction; VEGF: Vascular endothelial growth factor; VERDICT: Vascular, extracellular, and restricted diffusion for cytometry in tumors; vp: Fractional plasma volume; WB-DWI MRI: Whole-body diffusion-weighted magnetic resonance imaging; a: Stretching parameter

\section{Disclosures}

Anwar R Padhani

Disclosures: A.R.P. Activities related to the present article: disclosed no relevant relationships. Activities not related to the present article: software from Siemens Healthineers, personal fees from Jannsen Pharmaceuticals. Antonio Luna-Alcalá

Disclosures: A.L.A. Activities related to the present article: disclosed no relevant relationships. Activities not related to the present article: consultancy for Bracco and Philips, publication rights of several books for Springer. Other authors: no disclosures

\section{Authors' contributions}

Study concepts and design: RG, SB, ARP; Literature research and collection: All authors; Figures saved and prepared by: All authors; Manuscript preparation: All authors; Manuscript editing: RG, SB, ARP, JAV, ES; All authors read and approved the final manuscript.

\section{Competing interests}

The authors declare that they have no competing interests.

\section{Publisher's Note}

Springer Nature remains neutral with regard to jurisdictional claims in published maps and institutional affiliations.

\section{Author details}

'Department of Radiology, Hospital Clínico Universitario de Santiago de Compostela, Choupana s/n, 15706 Santiago de Compostela, Spain. ${ }^{2}$ Paul Strickland Scanner Centre, Mount Vernon Cancer Centre, Northwood, Middlesex, England HA6 2RN, UK. ${ }^{3}$ Department of Radiology, University Hospitals of Cleveland, Case Western Reserve University, Cleveland, OH, USA. ${ }^{4}$ MRI Unit, Clínica Las Nieves, Health Time, Jaén, Spain. ${ }^{5}$ Unidad de Gestión Clínica de Medicina Nuclear. IMIBIC. Hospital Reina Sofía. Universidad de Córdoba, Córdoba, Spain. ${ }^{6}$ Department of Radiology and Cancer Research UK Cambridge Center, Cambridge CB2 0QQ, UK. ${ }^{7}$ Department of Radiology, Clínica Girona and IDI, Lorenzana 36, 17002 Girona, Spain. ${ }^{8}$ Department of Radiology, Royal Marsden Hospital \& Institute of Cancer Research, Fulham Road, London SW3 6JJ, UK. ${ }^{9}$ Nuclear Medicine Department, Hospital Clínico Universitario de Santiago de Compostela, Choupana s/n, 15706 Santiago de Compostela, Galicia, Spain. ${ }^{10}$ Molecular Imaging Program, IDIS, USC, Santiago de Compostela, Galicia, Spain. ${ }^{11}$ Department of Radiology, Memorial Sloan-Kettering Cancer Center, Radiology, 1275 York Av. Radiology Academic Offices C-278, New York, NY 10065, USA. 
Received: 26 July 2018 Accepted: 8 November 2018 Published online: 04 March 2019

\section{References}

1. Hanahan D, Weinberg RA (2011) Hallmarks of cancer: the next generation. Cell 144:646-674

2. O'Neill AC, Alessandrino F, Tirumani SH, Ramaiya NH (2018) Hallmarks of Cancer in the Reading Room: A Guide for Radiologists. AJR Am J Roentgenol 11:1-15

3. Sala E, Mema E, Himoto $Y$ et al (2017) Unravelling tumor heterogeneity using next-generation imaging: radiomics, radiogenomics, and habitat imaging. Clin Radiol 72:3-10

4. Hricak H (2018) 2016 New Horizons Lecture: Beyond Imaging-Radiology of Tomorrow. Radiology 286:764-775

5. Winfield JM, Payne GS, deSouza NM (2015) Functional MRI and CT biomarkers in oncology. Eur J Nucl Med Mol Imaging 42:562-578

6. Gillies RJ, Anderson AR, Gatenby RA, Morse DL (2010) The biology underlying molecular imaging in oncology: from genome to anatome and back again. Clin Radiol 65:517-521

7. Spak DA, Plaxco JS, Santiago L, Dryden MJ, Dogan BE (2017) BI-RADS ${ }^{\oplus}$ fifth edition: A summary of changes. Diagn Interv Imaging 98:179-190

8. Kim YY, Choi JY, Sirlin CB, An C, Kim MJ (2018) Pitfalls and problems to be solved in the diagnostic CT/MRI Liver Imaging Reporting and Data System (LI-RADS). Eur Radiol. https://doi.org/10.1007/s00330-018-5641-6 [Epub ahead of print]

9. Manos D, Seely JM, Taylor J, Borgaonkar J, Roberts HC, Mayo JR (2014) The Lung Reporting and Data System (LU-RADS): a proposal for computed tomography screening. Can Assoc Radiol J 65:121-134

10. Tessler FN, Middleton WD, Grant EG (2018) Thyroid Imaging Reporting and Data System (TI-RADS): A User's Guide. Radiology 287:29-36

11. Campbell N, Rosenkrantz AB, Pedrosa I (2014) MRI phenotype in renal cancer: is it clinically relevant? Top Magn Reson Imaging 23:95-115

12. Karlo CA, Di Paolo PL, Chaim J et al (2014) Radiogenomics of clear cell rena cell carcinoma: associations between $C T$ imaging features and mutations. Radiology 270:464-471

13. Zhang Q, Eagleson R, Peters TM (2011) Volume visualization: a technical overview with a focus on medical applications. J Digit Imaging 24:640-664

14. Winter KS, Hofmann FO, Thierfelder KM et al (2018) Towards volumetric thresholds in RECIST 1.1: Therapeutic response assessment in hepatic metastases. Eur Radiol. https://doi.org/10.1007/s00330-018-5424-0 [Epub ahead of print]

15. Nielsen K, Rolff HC, Eefsen RL, Vainer B (2014) The morphological growth patterns of colorectal liver metastases are prognostic for overall survival. Mod Pathol 27:1641-1648

16. Anvari A, Barr RG, Dhyani M, Samir AE (2015) Clinical application of sonoelastography in thyroid, prostate, kidney, pancreas, and deep venous thrombosis. Abdom Imaging 40:709-722

17. Pepin KM, Ehman RL, McGee KP (2015) Magnetic resonance elastography (MRE) in cancer: Technique, analysis, and applications. Prog Nucl Magn Reson Spectrosc 90-91:32-48

18. Le Bihan D, Ichikawa S, Motosugi U (2017) Diffusion and Intravoxel Incoherent Motion MR Imaging-based Virtual Elastography: A Hypothesisgenerating Study in the Liver. Radiology 285:609-619

19. Cui XW, Chang JM, Kan QC, Chiorean L, Ignee A, Dietrich CF (2015) Endoscopic ultrasound elastography: Current status and future perspectives. World J Gastroenterol 21:13212-13224

20. Xu W, Shi J, Zeng X et al (2011) EUS elastography for the differentiation of benign and malignant lymph nodes: a meta-analysis. Gastrointest Endosc 74:1001-1009

21. Le Bihan D (2013) Apparent Diffusion Coefficient and Beyond: What Diffusion MR Imaging Can Tell Us about Tissue Structure. Radiology 268 318-322

22. Perez-Lopez R, Nava Rodrigues D, Figueiredo I et al (2018) Multiparametric Magnetic Resonance Imaging of Prostate Cancer Bone Disease: Correlation With Bone Biopsy Histological and Molecular Features. Invest Radiol 53: 96-102

23. Nilsson M, Englund E, Szczepankiewicz F, Danielle van Westen D, Sundgren PC (2018) Imaging brain tumor microstructure. Neuroimage. https://doi.org/ 10.1016/j.neuroimage.2018.04.075 [Epub ahead of print]
24. Bailey C, Collins DJ, Tunariu N et al (2018) Microstructure Characterization of Bone Metastases from Prostate Cancer with Diffusion MRI: Preliminary Findings. Front Oncol 8:26

25. Panagiotaki E, Walker-Samuel S, Siow B et al (2014) Noninvasive quantification of solid tumor microstructure using VERDICT MRI. Cancer Res 74:1902-1912

26. Low HM, Choi JY, Tan CH (2018) Pathological variants of hepatocellular carcinoma on MRI: emphasis on histopathologic correlation. Abdom Radiol (NY). https://doi.org/10.1007/s00261-018-1749-z [Epub ahead of print]

27. Koh DM, Collins DJ (2007) Diffusion-weighted MRI in the body: applications and challenges in oncology. AJR Am J Roentgenol 188:1622-1635

28. Patterson DM, Padhani AR, Collins DJ (2008) Technology insight: water diffusion MRI-a potential new biomarker of response to cancer therapy. Nat Clin Pract Oncol 5:220-233

29. Taouli B, Beer AJ, Chenevert T et al (2016) Diffusion-Weighted Imaging Outside the Brain: Consensus Statement From an ISMRM-Sponsored Workshop. J Magn Reson Imaging 44:521-540

30. Malayeri AA, El Khouli RH, Zaheer A et al (2011) Principles and applications of diffusion-weighted imaging in cancer detection, staging, and treatment follow-up. Radiographics 31:1773-1791

31. Taffel MT, Johnson EJ, Chandarana H (2017) Diffusion Quantification in Body Imaging. Top Magn Reson Imaging 26:243-249

32. Surov A, Meyer HJ, Wienke A (2017) Correlation between apparent diffusion coefficient (ADC) and cellularity is different in several tumors: a metaanalysis. Oncotarget 8:59492-59499

33. Surov A, Meyer HJ, Wienke A (2017) Correlation Between Minimum Apparent Diffusion Coefficient (ADCmin) and Tumor Cellularity: A Metaanalysis. Anticancer Res 37:3807-3810

34. Federau C (2017) Intravoxel incoherent motion MRI as a means to measure in vivo perfusion: A review of the evidence. NMR Biomed 30(11). https://doi. org/10.1002/nbm.3780 Epub 2017 Sep 8

35. lima M, Le Bihan D (2016) Clinical Intravoxel Incoherent Motion and Diffusion MR Imaging: Past, Present, and Future. Radiology 278:13-32

36. Le Bihan D (2017) What can we see with IVIM MRI? Neuroimage. https://doi. org/10.1016/j.neuroimage.2017.12.062 [Epub ahead of print]

37. Rosenkrantz AB, Padhani AR, Chenevert TL et al (2015) Body diffusion kurtosis imaging: Basic principles, applications, and considerations for clinical practice. J Magn Reson Imaging 42:1190-1202

38. Godley KC, Syer TJ, Toms AP et al (2018) Accuracy of high b-value diffusionweighted MRI for prostate cancer detection: a meta-analysis. Acta Radiol 59(1):105-113

39. Padhani AR, Liu G, Koh DM et al (2009) Diffusion-weighted magnetic resonance imaging as a cancer biomarker: consensus and recommendations. Neoplasia 1:102-125

40. Padhani AR (2011) Diffusion magnetic resonance imaging in cancer patient management. Semin Radiat Oncol 21:119-140

41. Padhani AR, Koh DM, Collins DJ (2011) Whole-body diffusion-weighted MR imaging in cancer: current status and research directions. Radiology 261: 700-718

42. Winfield JM, Payne GS, Weller A, deSouza NM (2016) DCE-MRI, DW-MRI, and MRS in Cancer: Challenges and Advantages of Implementing Qualitative and Quantitative Multi-parametric Imaging in the Clinic. Top Magn Reson Imaging 25:245-254

43. García-Figueiras R, Padhani AR, Baleato-González S (2016) Therapy Monitoring with Functional and Molecular MR Imaging. Magn Reson Imaging Clin N Am 24:261-288

44. Li SP, Padhani AR (2012) Tumor response assessments with diffusion and perfusion MRI. J Magn Reson Imaging 35:745-763

45. Li B, Li Q, Nie W, Liu S (2014) Diagnostic value of whole-body diffusionweighted magnetic resonance imaging for detection of primary and metastatic malignancies: a meta-analysis. Eur J Radiol 83:338-344

46. Kosmin M, Makris A, Joshi PV, Ah-See ML, Woolf D, Padhani AR (2017) The addition of whole-body magnetic resonance imaging to body computerised tomography changes treatment decisions in patients with metastatic breast cancer. Eur J Cancer 77:109-116

47. Morone M, Bali MA, Tunariu N et al (2017) Whole-Body MRI: Current Applications in Oncology. AJR Am J Roentgenol 209:W336-W349

48. Nievelstein RA, Littooij AS (2017) Whole-body MRI in paediatric oncology. Radiol Med 121:442-453

49. Koh DM, Blackledge M, Padhani AR et al (2012) Whole-body diffusionweighted MRI: tips, tricks, and pitfalls. AJR Am J Roentgenol 199:252-262 
50. Padhani AR, Gogbashian A (2011) Bony metastases: assessing response to therapy with whole-body diffusion MRI. Cancer Imaging 11:S129-S145

51. Barnes A, Alonzi R, Blackledge M et al (2018) UK quantitative WB-DWI technical workgroup: consensus meeting recommendations on optimisation, quality control, processing and analysis of quantitative wholebody diffusion-weighted imaging for cancer. Br J Radiol 91(1081):20170577. https://doi.org/10.1259/bjr.20170577 Epub 2017 Dec 7

52. deSouza NM, Winfield JM, Waterton JC et al (2018) Implementing diffusionweighted MRI for body imaging in prospective multicentre trials: current considerations and future perspectives. Eur Radiol 28:1118-1131

53. Padhani AR, Makris A, Gall P, Collins DJ, Tunariu N, de Bono JS (2014) Therapy monitoring of skeletal metastases with whole-body diffusion MRI. J Magn Reson Imaging 39:1049-1078

54. Padhani AR, Lecouvet FE, Tunariu N et al (2017) METastasis Reporting and Data System for Prostate Cancer: Practical Guidelines for Acquisition, Interpretation, and Reporting of Whole-body Magnetic Resonance Imagingbased Evaluations of Multiorgan Involvement in Advanced Prostate Cancer. Eur Urol 71:81-92

55. Koh DM, Collins DJ, Orton MR (2011) Intravoxel incoherent motion in body diffusion-weighted MRI: reality and challenges. AJR Am J Roentgenol 196: 1351-1361

56. Karampinos DC, Ruschke S, Dieckmeyer M et al (2018) Quantitative MRI and spectroscopy of bone marrow. J Magn Reson Imaging 47:332-353

57. Schraml C, Schmid M, Gatidis S et al (2015) Multiparametric analysis of bone marrow in cancer patients using simultaneous PET/MR imaging: Correlation of fat fraction, diffusivity, metabolic activity, and anthropometric data. J Magn Reson Imaging 42:1048-1056

58. Carmona R, Pritz J, Bydder M et al (2014) Fat composition changes in bone marrow during chemotherapy and radiation therapy. Int J Radiat Oncol Biol Phys 90:155-163

59. McSheehy PM, Weidensteiner C, Cannet C et al (2010) Quantified tumor T1 is a generic early-response imaging biomarker for chemotherapy reflecting cell viability. Clin Cancer Res 16:212-225

60. Adams LC, Ralla B, Jurmeister P et al (2019) Native T1 Mapping as an In Vivo Biomarker for the Identification of Higher-Grade Renal Cell Carcinoma: Correlation With Histopathological Findings. Invest Radiol 54:118-128

61. Weidensteiner C, Allegrini PR, Sticker-Jantscheff M, Romanet V, Ferretti S, McSheehy PM (2014) Tumor T1 changes in vivo are highly predictive of response to chemotherapy and reflect the number of viable tumor cells--a preclinical MR study in mice. BMC Cancer 14:88

62. Sabouri S, Chang SD, Savdie R et al (2017) Luminal Water Imaging: A New MR Imaging T2 Mapping Technique for Prostate Cancer Diagnosis. Radiology 284:451-459

63. Langer DL, van der Kwast TH, Evans AJ et al (2008) Intermixed normal tissue within prostate cancer: effect on MR imaging measurements of apparent diffusion coefficient and T2--sparse versus dense cancers. Radiology 249: 900-908

64. Wu LM, Zhao ZZ, Chen XX et al (2016) Comparison of T2* mapping with diffusion-weighted imaging in the characterization of low-grade vs intermediate-grade and high-grade prostate cancer. Br J Radiol 89:20151076

65. Seo M, Ryu JK, Jahng GH et al (2017) Estimation of T2* Relaxation Time of Breast Cancer: Correlation with Clinical, Imaging and Pathological Features. Korean J Radiol 18:238-248

66. Martens MH, Lambregts DM, Papanikolaou N et al (2016) Magnetization transfer imaging to assess tumor response after chemoradiotherapy in rectal cancer. Eur Radiol 26:390-397

67. Goldenberg JM, Pagel M (2018) Assessments of tumor metabolism with CEST MRI. NMR Biomed:e3943. https://doi.org/10.1002/nbm.3943 [Epub ahead of print]

68. Jones KM, Pollard AC, Pagel MD (2018) Clinical applications of chemical exchange saturation transfer (CEST) MRI. J Magn Reson Imaging 47:11-27

69. Paul J, Vogl TJ, Mbalisike EC (2014) Oncological applications of dual-energy computed tomography imaging. J Comput Assist Tomogr 38:834-842

70. Kosmala A, Weng AM, Heidemeier A et al (2018) Multiple Myeloma and Dual-Energy CT: Diagnostic Accuracy of Virtual Noncalcium Technique for Detection of Bone Marrow Infiltration of the Spine and Pelvis. Radiology 286:205-213

71. LeBleu VS (2015) Imaging the Tumor Microenvironment. Cancer J 21 174-178

72. Chen F, Zhuang $X$, Lin $L$ et al (2015) New horizons in tumor microenvironment biology: challenges and opportunities. BMC Med 13:45
73. Gillies RJ, Raghunand N, Karczmar GS, Bhujwalla ZM (2002) MRI of the tumor microenvironment. J Magn Reson Imaging 16:430-450

74. Aarntzen EH, Srinivas M, Radu CG et al (2013) In vivo imaging of therapyinduced anti-cancer immune responses in humans. Cell Mol Life Sci 70: 2237-2257

75. Fleming IN, Manavaki R, Blower PJ et al (2015) Imaging tumor hypoxia with positron emission tomography. Br J Cancer 112:238-250

76. Hallac RR, Zhou H, Pidikiti R et al (2014) Correlations of noninvasive BOLD and TOLD MRI with $\mathrm{pO} 2$ and relevance to tumor radiation response. Magn Reson Med 71:1863-1673

77. Padhani AR, Krohn KA, Lewis JS, Alber M (2007) Imaging oxygenation of human tumors. Eur Radiol 17:861-872

78. Lapi SE, Lewis JS, Dehdashti F (2015) Evaluation of hypoxia with copper-labeled diacetyl-bis(N-methylthiosemicarbazone). Semin Nucl Med 45:177-185

79. Hoskin PJ, Carnell DM, Taylor NJ et al (2007) Hypoxia in prostate cancer: correlation of BOLD-MRI with pimonidazole immunohistochemistry-initial observations. Int J Radiat Oncol Biol Phys 68:1065-1071

80. White DA, Zhang Z, Li L et al (2016) Developing oxygen-enhanced magnetic resonance imaging as a prognostic biomarker of radiation response. Cancer Lett 380:69-77

81. Gillies RJ, Raghunand N, Garcia-Martin ML, Gatenby RA (2004) pH imaging A review of $\mathrm{pH}$ measurement methods and applications in cancers. IEEE Eng Med Biol Mag 23:57-64

82. Lin G, Keshari KR, Park JM (2017) Cancer Metabolism and Tumor Heterogeneity: Imaging Perspectives Using MR Imaging and Spectroscopy. Contrast Media Mol Imaging 2017:6053879

83. Fuss TL, Cheng LL (2016) Metabolic Imaging in Humans. Top Magn Reson Imaging 25:223-235

84. Zhu A, Shim H (2011) Current molecular imaging positron emitting radiotracers in oncology. Nucl Med Mol Imaging 45:1-14

85. Deroose CM, Hindié E, Kebebew E et al (2016) Molecular Imaging of Gastroenteropancreatic Neuroendocrine Tumors: Current Status and Future Directions. J Nucl Med 57:1949-1956

86. Pereira PMR, Abma L, Henry KE, Lewis JS (2018) Imaging of human epidermal growth factor receptors for patient selection and response monitoring - From PET imaging and beyond. Cancer Lett 419:139-151

87. Rischpler C, Beck TI, Okamoto S et al $(2018){ }^{68}$ Ga-PSMA-HBED-CC Uptake in Cervical, Celiac, and Sacral Ganglia as an Important Pitfall in Prostate Cancer PET Imaging. J Nucl Med 59:1406-1411

88. Eiber M, Fendler WP, Rowe SP et al (2017) Prostate-Specific Membrane Antigen Ligands for Imaging and Therapy. J Nucl Med 58:67S-76S

89. Walenkamp AME, Lapa C, Herrmann K, Wester HJ (2017) CXCR4 Ligands: The Next Big Hit? J Nucl Med 58:77S-82S

90. Vander Heiden MG, DeBerardinis RJ (2017) Understanding the Intersections between Metabolism and Cancer Biology. Cell 168:657-669

91. Sai KKS, Zachar Z, Bingham PM, Mintz A (2017) Metabolic PET Imaging in Oncology. AJR Am J Roentgenol 209:270-276

92. Challapalli A, Aboagye EO (2016) Positron Emission Tomography Imaging of Tumor Cell Metabolism and Application to Therapy Response Monitoring. Front Oncol 6:44

93. Liberti MV, Locasale JW (2016) The Warburg Effect: How Does it Benefit Cancer Cells? Trends Biochem Sci 41:211-218

94. Lopci E, Nanni C, Castellucci P et al (2010) Imaging with non-FDG PET tracers: outlook for current clinical applications. Insights Imaging 1:373-385

95. Rauscher I, Eiber M, Souvatzoglou M, Schwaiger M, Beer AJ (2014) PET/MR in Oncology: Non-18F-FDG Tracers for Routine Applications. J Nucl Med 55:25S-31S

96. Barrington SF, Kluge R (2017) FDG PET for therapy monitoring in Hodgkin and non-Hodgkin lymphomas. Eur J Nucl Med Mol Imaging 44(Suppl 1):97-110

97. Gámez-Cenzano C, Pino-Sorroche F (2014) Standardization and quantification in FDG-PET/CT imaging for staging and restaging of malignant disease. PET Clin 9:117-127

98. Hicks RJ, Hofman MS (2012) Is there still a role for SPECT-CT in oncology in the PET-CT era? Nat Rev Clin Oncol 9:712-720

99. Gambhir SS, Czernin J, Schwimmer J, Silverman DH, Coleman RE, Phelps ME (2001) A tabulated summary of the FDG PET literature. J Nucl Med 42:1S-93S

100. Hillner BE, Siegel BA, Liu D et al (2008) Impact of positron emission tomography/computed tomography and positron emission tomography (PET) alone on expected management of patients with cancer: initial results from the National Oncologic PET Registry. J Clin Oncol 26:2155-2161 
101. Saif MW, Tzannou I, Makrilia N, Syrigos K (2010) Role and cost effectiveness of PET/CT in management of patients with cancer. Yale J Biol Med 83:53-65

102. Czernin J, Allen-Auerbach M, Schelbert HR (2006) Improvements in cancer staging with PET/CT: literature-based evidence as of September 2006. J Nucl Med 48:78S-88S

103. Sridhar P, Mercier G, Tan J, Truong MT, Daly B, Subramaniam RM (2014) FDG PET metabolic tumor volume segmentation and pathologic volume of primary human solid tumors. AJR Am J Roentgenol 202:1114-1119

104. Teixeira SC, Rebolleda JF, Koolen BB et al (2016) Evaluation of a HangingBreast PET System for Primary Tumor Visualization in Patients With Stage I-III Breast Cancer: Comparison With Standard PET/CT. AJR Am J Roentgenol 206:1307-1314

105. Ehman EC, Johnson GB, Villanueva-Meyer JE et al (2017) PET/MRI: Where might it replace PET/CT? J Magn Reson Imaging 46:1247-1262

106. Fraum TJ, Fowler KJ, McConathy J (2016) PET/MRI: Emerging Clinical Applications in Oncology. Acad Radiol 23(2):220-236

107. Bailey DL, Pichler BJ, Gückel B et al (2018) Combined PET/MRI: Global Warming-Summary Report of the 6th International Workshop on PET/MRI, March 27-29, 2017, Tübingen, Germany. Mol Imaging Biol 20:4-20

108. García-Figueiras R, Baleato-González S, Padhani AR et al (2016) Proton magnetic resonance spectroscopy in oncology: the fingerprints of cancer? Diagn Interv Radiol 22:75-89

109. Martín Noguerol T, Sánchez-González J, Martínez Barbero JP, GarcíaFigueiras R, Baleato-González S, Luna A (2016) Clinical Imaging of Tumor Metabolism with ${ }^{1} \mathrm{H}$ Magnetic Resonance Spectroscopy. Magn Reson Imaging Clin N Am 24:57-86

110. Zaccagna F, Grist JT, Deen SS et al (2018) Hyperpolarized carbon-13 magnetic resonance spectroscopic imaging: a clinical tool for studying tumor metabolism. Br J Radiol:20170688. https://doi.org/10.1259/bjr. 20170688 [Epub ahead of print]

111. Glunde K, Bhujwalla ZM (2011) Metabolic tumor imaging using magnetic resonance spectroscopy. Semin Oncol 38:26-41

112. Glunde K, Jiang L, Moestue SA, Gribbestad IS (2011) MRS and MRSI guidance in molecular medicine: targeting and monitoring of choline and glucose metabolism in cancer. NMR Biomed 24:673-690

113. Verma A, Kumar I, Verma N, Aggarwal P, Ojha R (2016) Magnetic resonance spectroscopy- Revisiting the biochemical and molecular milieu of brain tumors. BBA Clin 5:170-178

114. Wang P, Guo YM, Liu M et al (2008) A meta-analysis of the accuracy of prostate cancer studies which use magnetic resonance spectroscopy as a diagnostic tool. Korean J Radiol 9:432-438

115. Sardanelli F, Carbonaro LA, Montemezzi S, Cavedon C, Trimboli RM (2016) Clinical Breast MR Using MRS or DWI: Who Is the Winner? Front Oncol 6:217

116. Brindle KM, Bohndiek SE, Gallagher FA, Kettunen MI (2011) Tumor imaging using hyperpolarized $13 \mathrm{C}$ magnetic resonance spectroscopy. Magn Reson Med 66:505-519

117. Peck M, Pollack HA, Friesen A et al (2015) Applications of PET imaging with the proliferation marker [18F]-FLT. Q J Nucl Med Mol Imaging 59:95-104

118. Surov A, Meyer HJ, Wienke A (2017) Associations between apparent diffusion coefficient (ADC) and KI 67 in different tumors: a meta-analysis. Part 1: ADCmean. Oncotarget 8:75434-75444

119. Surov A, Meyer HJ, Höhn AK et al (2017) Correlations between intravoxel incoherent motion (IVIM) parameters and histological findings in rectal cancer: preliminary results. Oncotarget 8:21974-21983

120. García-Figueiras R, Padhani AR, Beer AJ et al (2015) Imaging of Tumor Angiogenesis for Radiologists--Part 1: Biological and Technical Basis. Curr Probl Diagn Radiol 44:407-424

121. García-Figueiras R, Padhani AR, Beer AJ et al (2015) Imaging of Tumor Angiogenesis for Radiologists--Part 2: Clinical Utility. Curr Probl Diagn Radiol 44:425-436

122. Chong WK, Papadopoulou V, Dayton PA (2018) Imaging with ultrasound contrast agents: current status and future. Abdom Radiol (NY). https://doi. org/10.1007/s00261-018-1516-1 [Epub ahead of print]

123. Salem A, O'Connor JPB (2016) Assessment of Tumor Angiogenesis: Dynamic Contrast-enhanced MR Imaging and Beyond. Magn Reson Imaging Clin N Am 24:45-56

124. Miles KA, Lee TY, Goh V et al (2012) Experimental Cancer Medicine Centre Imaging Network Group. Current status and guidelines for the assessment of tumor vascular support with dynamic contrast-enhanced computed tomography. Eur Radiol 22:1430-1441
125. Cuenod CA, Balvay D (2013) Perfusion and vascular permeability: basic concepts and measurement in DCE-CT and DCE-MRI. Diagn Interv Imaging 94:1187-1204

126. García-Figueiras R, Goh VJ, Padhani AR et al (2013) CT perfusion in oncologic imaging: a useful tool? AJR Am J Roentgenol 200:8-19

127. Thaiss WM, Haberland U, Kaufmann S et al (2016) lodine concentration as a perfusion surrogate marker in oncology: Further elucidation of the underlying mechanisms using Volume Perfusion CT with 80 kVp. Eur Radiol 26:2929-2936

128. Dietrich CF, Averkiou MA, Correas JM, Lassau N, Leen E, Piscaglia F (2012) An EFSUMB introduction into dynamic contrast-enhanced ultrasound (DCEUS) for quantification of tumor perfusion. Ultraschall Med 33:344-351

129. Haller S, Zaharchuk G, Thomas DL, Lovblad KO, Barkhof F, Golay X (2016) Arterial Spin Labeling Perfusion of the Brain: Emerging Clinical Applications. Radiology 281:337-356

130. Lassau N, Chami L, Chebil M et al (2011) Dynamic contrast-enhanced ultrasonography (DCE-US) and anti-angiogenic treatments. Discov Med 11:18-24

131. Rybczynska AA, Boersma HH, de Jong S et al (2018) Avenues to molecular imaging of dying cells: Focus on cancer. Med Res Rev. https://doi.org/10. 1002/med.21495 [Epub ahead of print]

132. Blankenberg FG, Norfray JF (2011) Multimodality molecular imaging of apoptosis in oncology. AJR Am J Roentgenol 197:308-317

133. Delikatny EJ, Chawla S, Leung DJ, Poptani H (2011) MR-visible lipids and the tumor microenvironment. NMR Biomed 24:592-611

134. Papaevangelou E, Almeida GS, Jamin Y, Robinson SP, deSouza NM (2015) Diffusion-weighted MRI for imaging cell death after cytotoxic or apoptosisinducing therapy. Br J Cancer 112:1471-1479

135. De Sousa EMF, Vermeulen L, Fessler E, Medema JP (2013) Cancer heterogeneity--a multifaceted view. EMBO Rep 14:686-695

136. Gatenby RA, Grove O, Gillies RJ (2013) Quantitative imaging in cancer evolution and ecology. Radiology 269:8-15

137. Gillies RJ, Kinahan PE, Hricak H (2016) Radiomics: images are more than pictures, they are data. Radiology 278:563-577

138. O'Connor JP, Rose CJ, Waterton JC, Carano RA, Parker GJ, Jackson A (2015) Imaging intratumor heterogeneity: role in therapy response, resistance, and clinical outcome. Clin Cancer Res 21:249-245

139. Davnall F, Yip CS, Ljungqvist G et al (2012) Assessment of tumor heterogeneity: an emerging imaging tool for clinical practice? Insights Imaging 3:573-589

140. O'Connor JP, Aboagye EO, Adams JE et al (2017) Imaging biomarker roadmap for cancer studies. Nat Rev Clin Oncol 14:169-186

141. Shukla-Dave A, Obuchowski NA, Chenevert TL et al (2018) Quantitative imaging biomarkers alliance (QIBA) recommendations for improved precision of DWI and DCE-MRI derived biomarkers in multicenter oncology trials. J Magn Reson Imaging. https://doi.org/10.1002/jmri.26518 [Epub ahead of print]

142. Huang EP, Lin Fl, Shankar LK (2017) Beyond Correlations, Sensitivities, and Specificities: A Roadmap for Demonstrating Utility of Advanced Imaging in Oncology Treatment and Clinical Trial Design. Acad Radiol 24:1036-1049

143. Dregely I, Prezzi D, Kelly-Morland C, Roccia E, Neji R, Goh V (2018) Imaging biomarkers in oncology: Basics and application to MRI. J Magn Reson Imaging 48:13-26

144. Mankoff DA, Farwell MD, Clark AS, Pryma DA (2017) Making Molecular Imaging a Clinical Tool for Precision Oncology: A Review. JAMA Oncol 3: 695-701

145. Larue RT, Defraene G, De Ruysscher D, Lambin P, van Elmpt W (2017) Quantitative radiomics studies for tissue characterization: a review of technology and methodological procedures. Br J Radiol 90:20160665

146. Lambin P, Leijenaar RTH, Deist TM et al (2017) Radiomics: the bridge between medical imaging and personalized medicine. Nat Rev Clin Oncol 14:749-762

147. Yip SS, Aerts HJ (2016) Applications and limitations of radiomics. Phys Med Biol 61:R150-R166

148. Avanzo M, Stancanello J, El Naqa I (2017) Beyond imaging: The promise of radiomics. Phys Med 38:122-139

149. Pinker K, Shitano F, Sala E et al (2018) Background, current role, and potential applications of radiogenomics. J Magn Reson Imaging 47:604-620

150. Jansen RW, van Amstel P, Martens RM (2018) Non-invasive tumor genotyping using radiogenomic biomarkers, a systematic review and oncology-wide pathway analysis. Oncotarget 9:20134-20155 
151. Limkin EJ, Sun R, Dercle $L$ et al (2017) Promises and challenges for the implementation of computational medical imaging (radiomics) in oncology. Ann Oncol 28:1191-1206

152. Kim JY, Gatenby RA (2017) Quantitative Clinical Imaging Methods for Monitoring Intratumoural Evolution. Methods Mol Biol 1513:61-81

153. Cox VL, Bhosale P, Varadhachary GR et al (2017) Cancer Genomics and Important Oncologic Mutations: A Contemporary Guide for Body Imagers. Radiology 283:314-340

154. Shaikh F, Franc B, Allen E et al (2018) Translational Radiomics: Defining the Strategy Pipeline and Considerations for Application-Part 1: From Methodology to Clinical Implementation. J Am Coll Radiol 15:538-542

155. Shaikh F, Franc B, Allen E et al (2018) Translational Radiomics: Defining the Strategy Pipeline and Considerations for Application-Part 2: From Clinical Implementation to Enterprise. J Am Coll Radiol 15:543-549

156. Chennubhotla C, Clarke LP, Fedorov A et al (2017) An Assessment of Imaging Informatics for Precision Medicine in Cancer. Yearb Med Inform 26: $110-119$

157. Erickson BJ, Korfiatis P, Akkus Z, Kline TL (2017) Machine Learning for Medical Imaging. Radiographics 37:505-515

158. Dreyer KJ, Geis JR (2017) When Machines Think: Radiology's Next Frontier. Radiology 285:713-718

159. Shafiee A, Atala A (2016) Printing Technologies for Medical Applications. Trends Mol Med 22:254-265

160. Mankoff DA, Dunnwald LK, Partridge SC, Specht JM (2009) Blood flowmetabolism mismatch: good for the tumor, bad for the patient. Clin Cancer Res 15:5294-5296

161. Jadvar H, Chen X, Cai W, Mahmood U (2018) Radiotheranostics in Cancer Diagnosis and Management. Radiology 286:388-400

162. Stasinopoulos I, Penet MF, Chen Z, Kakkad S, Glunde K, Bhujwalla ZM (2011) Exploiting the tumor microenvironment for theranostic imaging. NMR Biomed 24:636-647

\section{Submit your manuscript to a SpringerOpen ${ }^{\circ}$ journal and benefit from:}

- Convenient online submission

- Rigorous peer review

- Open access: articles freely available online

- High visibility within the field

- Retaining the copyright to your article

Submit your next manuscript at $\boldsymbol{\nabla}$ springeropen.com 